\title{
The semantics and acquisition of number words: integrating linguistic and developmental perspectives
}

\author{
Julien Musolino \\ Department of Speech and Hearing Sciences, Indiana University, 200 S. Jordan Avenue, \\ Bloomington, IN 47405-7002, USA
}

Received 16 July 2003; accepted 23 September 2003

\begin{abstract}
This article brings together two independent lines of research on numerally quantified expressions, e.g. two girls. One stems from work in linguistic theory and asks what truth conditional contributions such expressions make to the utterances in which they are used - in other words, what do numerals mean? The other comes from the study of language development and asks when and how children learn the meaning of such expressions. My goal is to show that when integrated, these two perspectives can both constrain and enrich each other in ways hitherto not considered. Specifically, work in linguistic theory suggests that in addition to their 'exactly n' interpretation, numerally quantified NPs such as two hoops can also receive an 'at least n' and an 'at most n' interpretation, e.g. you need to put two hoops on the pole to win (i.e. at least two hoops) and you can miss two shots and still win (i.e. at most two shots). I demonstrate here through the results of three sets of experiments that by the age of 5 children have implicit knowledge of the fact that expressions like $t w o ~ N$ can be interpreted as 'at least two N' and 'at most two N' while they do not yet know the meaning of corresponding expressions such as at least/most two $N$ which convey these senses explicitly. I show that these results have important implications for theories of the semantics of numerals and that they raise new questions for developmental accounts of the number vocabulary.
\end{abstract}

(C) 2003 Elsevier B.V. All rights reserved.

Keywords: Language acquisition; Number words; Scalar terms; Semantics; Pragmatics

E-mail address: musolino@indiana.edu (J. Musolino). 


\section{Introduction}

This article is concerned with the meaning and the acquisition of numerally quantified expressions, e.g. two cats. Scholars interested in how children learn the meanings of words have long noticed that the so-called 'number words' pose a special problem. As several investigators have pointed out, number words, unlike words such as dog or house, do not refer to individuals or properties of individuals like fluffy or large, for example (Bloom, 2000; Dehaene, 1997). Instead, they express generalizations about sets of individuals. ${ }^{1}$ So, for example, Three dogs licked my face says nothing about the properties that any of the individual dogs may possess; rather, the sentence expresses the fact that the intersection of the set of dogs and the set of individuals that have the property of licking my face is a set of cardinality 3. As Paul Bloom (2000) observes, the problem with sets, and properties of sets, is that "Sets are notoriously abstract entities. One can see and hear cats, but nobody has ever been wakened in the middle of the night by the yowling of a set. The apprehension of sets might therefore require some cognitive capacity above and beyond the normal apprehension of entities in the world..." (p. 213). To further complicate matters, number words have a complex distribution and they can be used in a wide range of contexts under a variety of guises (Fuson, 1988). ${ }^{2}$

In light of the problems associated with the acquisition of the number vocabulary, it is natural to ask how children manage to become linguistically competent in this domain. In their groundbreaking study, Gelman and Gallistel (1978) (henceforth G\&G) proposed that successful acquisition of the number vocabulary involves, inter alia, an a priori understanding of the basic principles underlying counting. Thus, G\&G argue that "The young child obtains representations of numerosity by counting ... The child's ability to count is governed by a set of counting principles. These principles constitute a scheme in that they both guide and motivate the development of proficiency at counting." (p. 243). ${ }^{3}$

Developmental psychologists generally agree that the principles identified by G\&G are indeed the relevant ones. However, opinions differ sharply over the exact role that these principles play in explaining how children learn the meaning of number words. As Freeman, Antonucci, and Lewis (2000) remark "There is universal agreement that Gelman and Gallistel (1978) defined the principles governing the domain ..., but there is great controversy over the role of principles in explaining development ...” (p. 72). The controversy revolves around the question of whether the counting principles identified by

\footnotetext{
1 As do quantificational determiners more generally.

2 Fuson (1988) distinguishes seven possible uses of number words: cardinal (e.g. two cats, three dogs), ordinal (e.g. the third house on the left, the second day of the week), measure (e.g. two inches of rope, three acres), counting (one, two, three (pointing to objects in a row)), sequence (e.g. One, two, three, go!), symbolic (e.g. 2, 3, 4 , etc.) and non-numerical (e.g. bus 201, flight 856).

${ }^{3}$ G\&G identified five such principles. Three of these principles specify 'how to count' and the other two 'what to count'. The 'how to count' principles include the 'one-one principle' - requiring a one-to-one correspondence between items in a display and number tags, the 'stable order principle' - requiring that number tags be ordered in the same sequence across trials and the 'cardinal principle' - requiring that the last tag used in a sequence correspond to the cardinality of the set of items in the sequence. The 'what to count' principles are the 'abstraction principle' - expressing the idea that any kind of object can be counted and the 'order-irrelevance' principle stating that counting can start with any object in a set (provided of course that the other counting principles aren't violated).
} 
G\&G are what children rely on to acquire the meaning of number words, i.e. the 'Principles before skill' view (Gallistel \& Gelman, 1992; Gelman \& Gallistel, 1978; Gelman \& Meck, 1983), or whether children abstract these principles through experience with the number words, the 'Skill before principles' view (Briars \& Siegler, 1984; Fuson, 1988 among others).

In sum, although opinions may differ on the question of how children acquire the meaning of number words, there seems to be no disagreement over what children eventually have to learn; namely that number words refer to precise, constant and unique numerosities ${ }^{4}$ - the implicit assumption being that number words have an 'exact' semantics. To quote the authors of a recent study on the acquisition of number words, “... children view number words as denoting specific, unique numerosities ..." (Sarnecka \& Gelman, in press).

Interestingly, the assumption regarding the 'exact' and 'invariant' meaning of numerals, which seems to be part and parcel of every psychological account of number word acquisition, has been the source of much debate among scholars approaching number words from a linguistic perspective (Atlas, 1990; Carston, 1985, 1998; Horn, 1972, 1989, 1992; Kadmon, 2001; Koenig, 1991; Richardson \& Richardson, 1990; Sadock, 1984 among others). Here, the central problem has been to determine the truth conditional contributions that number words make to the utterances in which they are used - in other words, what number words mean. Moreover, the standard orthodoxy in much of the philosophical and linguistic literature is that numerals do not have an 'exact' semantics; that is, they do not refer to precise, unique and constant numerosities. On the standard view in the logico-semantic literature (Horn, 1972, 1989), two dogs does not literally mean exactly two dogs, but rather at least two dogs. Thus, John has two dogs is semantically true, even if John has three, four or fifty dogs.

Linguists have also noticed that numerals give rise to three different interpretations, depending on the contexts in which they are used. Consider the examples in (1-3) below.

(1) A: How many mistakes did you make?

B: I made three mistakes.

(2) You need to make three mistakes to be allowed to take the test again.

(3) You can make three mistakes and still pass this test.

While the most natural interpretation of three mistakes in (1) is one on which it is construed as exactly three mistakes, the same phrase in (2) and (3) has a distinctly different flavor. In (2), three mistakes is interpreted as at least three mistakes. In other words, four, five or six mistakes will also allow you to take the test again. Finally, three mistakes in (3) is most naturally interpreted as at most three mistakes. That is, any number of mistakes lower than three will allow you to pass the test. What are we to make of such facts? Should one conclude that there are three threes, one meaning 'exactly three', the other 'at least three' and the third one 'at most three'? Or is there really only one three? If so, what is

\footnotetext{
${ }^{4}$ To the extent, of course, that they are used to refer to numerosity (see footnote 1 ).
} 
the literal meaning of three - or any other numeral for that matter - and how can one derive the other interpretations from the literal meaning? These, and related questions, lie at the heart of current discussions of the semantics/pragmatics of number terms and although the range of possible solutions has now been limited to a few well-defined options, many of these question remain open (see Carston, 1998 for a review).

So far, the two lines of inquiry discussed above, represented by work in developmental psychology and theoretical linguistics, have had virtually no influence on one another. This is not too surprising, however. To be sure, a few exceptions notwithstanding, developmental psychologists do not typically worry about fine points of grammatical analysis; nor are philosophers and theoretical linguists particularly well-known for their concern over developmental issues. My goal in this paper is to show that when one worries about both fine points of grammar and developmental issues, the picture that emerges is one which is substantially more interesting for both sides. I begin by showing that the facts observed by linguists and philosophers, when considered from the perspective of language acquisition, raise new and interesting developmental questions. Specifically, I ask when and how children learn that numerally quantified expressions can receive 'non-exact' interpretations, i.e. 'at least n' and 'at most n'. Using the tools of experimental psychology, I then show how these questions can be addressed experimentally. Moreover, I show that the results from such experimentation, in turn, can be used to tease apart competing theoretical analyses of the semantics of numerals. Specifically, I demonstrate that these results, when combined with those of Papafragou and Musolino (2003), provide compelling evidence against the standard, neo-Gricean analysis of number terms.

Thus, on a more general level, I hope to demonstrate once again that in the domain of language acquisition, the goals of linguistic theory and those of developmental psychology are inexorably intertwined: questions pertaining to the acquisition of language are best pursued with a prior understanding of the system to be acquired, i.e. language (Chomsky, 1959, 1975), and, reciprocally, work in linguistic theory does not reach its full explanatory force until the models proposed face the challenges posed by the need to explain language acquisition (Chomsky, 1965; Hornstein \& Lightfoot, 1981).

\section{Theoretical background}

To preface the experimental sections of the paper, I begin with a discussion of the key theoretical concepts necessary for a proper understanding of the linguist behavior of numerally quantified NPs. Because numerals are generally regarded as scalar terms in the semantics and pragmatics literature, I begin in Section 2.1 with a discussion of the phenomenon of scalar implicature, as described within the framework developed by Grice (1989). Section 2.2 presents the standard, neo-Gricean account of numerals developed by Horn (1972, 1989). Finally, in Section 2.3, I review a number of problems for the neo-Gricean account of numerals and I briefly discuss recent alternatives to it. 


\subsection{Scalar implicature}

A well-known observation regarding the nature of human communication is that speakers often intend to convey far more than what is directly encoded by their utterances and that hearers go beyond the truth conditional content of an utterance, i.e. what is said, and manage to retrieve the intended message, i.e. what is meant. In the classic framework developed by Paul Grice, the gap between what is said (the truth conditional content of an utterance) and what is meant (the message ultimately conveyed by an utterance) is bridged by an aspect of speaker meaning known as implicature.

Perhaps the most widely studied type of conversational implicature is the class of so-called scalar implicatures which typically arise in examples like (4). Notice that the speaker's use of some in (4) invites the inference in (5).

(4) Some of my friends are unhappy about the war.

(5) Not all of my friends are unhappy about the war.

The reasoning behind the inference in (5) has long been clear, at least intuitively.

If I say to any one, "I saw some of your children today", he might be justified in inferring that I did not see them all, not because the words mean it, but because, if I had seen them all, it is most likely that I should have said so: even though this cannot be presumed unless it is presupposed that I must have known whether the children I saw were all or not. (Mill, 1867, p. 501)

In Grice's system, this intuition follows from the inherently cooperative nature of communicative behavior, captured by Grice's Cooperative Principle.

Cooperative Principle:

Make your conversational contribution such as is required, at the stage at which it occurs, by the accepted purpose or direction of the talk exchange. (Grice, 1989, p. 26).

This principle, in turn, is decomposed into Grice's famous maxims governing conversational exchanges. One such maxim is the maxim of quantity, given below.

Maxim of quantity

(1) Make your contribution as informative as required (for the current purposes of the exchange).

(2) Do not make your contribution more informative than is required (Grice, 1989, pp. 26-27).

In Grice's scheme, SI follows from the maxim of quantity and in particular the submaxim in (1) above. Assuming that the speaker is trying to be cooperative, the fact that (s)he uses the weaker term (i.e. some) in some of my friends are unhappy about the war, invites 
the inference that (s)he is not in a position to offer an informationally stronger statement, i.e. All of my friends are unhappy about the war.

Notice here that 'informational strength' is defined in terms of the asymmetric entailment relations holding between equivalent propositions containing each of the terms on a given scale, e.g. $\langle$ some, all $\rangle$, such that stronger, i.e. more informative terms, yield propositions that are true in a narrower set of circumstances as compared to weaker, i.e. less informative terms (Horn, 1972). The facts are illustrated in (6).

(6) All of my friends are unhappy about the war. $\Rightarrow$ Some of my friends are unhappy about the war.

In other words, if it is true that all of my friends are unhappy about the war, it is necessarily true that some of them are unhappy about the war. On the other hand, the fact that some of my friends are unhappy about the war does not necessarily entail that all of then are.

Because scalar implicatures are inferentially derived, and not part of an expression's truth conditional content, they can easily be cancelled, as shown in (7).

(7) Some of my friends are unhappy about the war. In fact, all of them are.

In addition to being cancelable, scalar implicatures have a number of other properties which are not directly relevant to our current purposes (see Levinson, 2000, p. 15 for an exhaustive list). Finally, it should be pointed out that several accounts of scalar implicature have been advanced since Grice's original proposal (Carston, 1998; Gazdar, 1979; Harnish, 1976; Hirschberg, 1985; Horn, 1972; Levinson, 2000; Sperber \& Wilson, 1995).

\subsection{The neo-Gricean view of numerals}

Horn $(1972,1989)$ proposes to extend the Gricean approach to the case of numerals. First, notice that numerals form a scale in which the following asymmetric entailment pattern holds:

(8) Joe has four children. $\Rightarrow$ Joe has three $\{$ two, one $\}$ children.

In other words, if it is true that John has four children, it necessarily follows that John also has three children, two children, etc. Moreover, the typical scale reversing property of sentential negation also applies to numerals, as shown in (9).

(9) Joe doesn't have three children. $\Rightarrow$ Joe doesn't have four $\{$ five, six ... $\}$ children.

On the view advocated by Horn, Joe has three children literally means that Joe has at least three children. That is, the sentence Joe has three children is semantically true just in case Joe has three or more children. In other words, numerals, just like other scalar terms, ${ }^{5}$ have

\footnotetext{
5 This of course excludes terms whose scales are not based on entailment relations (see Levinson, 2000 for discussion).
} 
a lower bounded semantics, as shown in (10). On this view, the 'exact' interpretation of numerals, i.e. the fact that Joe has three children is typically interpreted to mean that Joe has exactly three children, is derived by the interaction of the numeral's lower bounded semantics with an upward bounding implicature, as shown in (11).

$$
\begin{array}{ll}
\text { (10) } \quad \text { two }=[2, \infty[ & \begin{array}{l}
\text { (semantically) } \\
\text { (11) } \quad \text { two }=[2) \ldots 3 \ldots 4 \ldots
\end{array} \\
\text { (pragmatically, where ')' represents an upward bounding } \\
\text { implicature) }
\end{array}
$$

Thus, just as Some of my friends liked the movie is typically interpreted to convey the implicature that not all my friends liked the movie, Joe has three children is typically interpreted to convey the implicature that Joe doesn't have more than three children hence the 'exact' reading of the numeral.

In addition to providing a unified treatment of scalar terms, the neo-Gricean approach offers an elegant account of two sets of facts pertaining to numerals. First, if the mechanism giving rise to the 'exact' interpretation of numerals does indeed involve pragmatic implicature, one would expect the numerals' upper boundary to be cancelable (see Section 2.1). As Horn points out, this expectation is indeed born out. The examples below are from Horn (1989, p. 215).

(12) Pat has three children and possibly four.

three children and for all I know four.

three children if not four.

three or even four children.

three, indeed four children.

Second, the neo-Gricean approach naturally accounts for the behavior of numerals under negation. Consider the example in (13).

(13) Pat doesn't have three children.

As Horn points out, examples like (13) are typically interpreted to mean that Pat has fewer than three children. In other words, sentential negation cancels the numeral's lower boundary. This is in fact exactly what one should expect: since the lower boundary is part of the truth conditional content of the numeral, it is therefore predicted to interact with other truth conditional operators such as negation.

More problematic on this view is the availability of examples like (14), in which negation cancels the numeral's upper boundary. The problem here is that the upper boundary is not part of the semantic, i.e. truth conditional content of the numeral (it is only pragmatically derived) and so it should not be able to interact with truth conditional operators such as negation.

(14) Pat doesn't have three children, he has four.

The solution proposed by Horn is that examples like (14) do not involve regular (contradictory) negation but rather what Horn (1992) calls metalinguistic negation, 
"a device for objecting to a previous utterance on any grounds whatever, including its phonetic or morphological form ...its register or style ...or its focus, point of view, or connotative meaning" (p. 166). More specifically, Horn (1989, p. 377) defines metalinguistic negation as in (15) and offers the examples in (16) and (17) (Horn, 1992, pp. 167-169).

(15) “Apparent sentence negation represents either a descriptive truth-functional operator, taking a proposition $\phi$ into a proposition not- $\phi$ (or a predicate $\mathrm{P}$ into a predicate not-P), or a metalinguistic operator which can be glossed 'I object to U', where $\mathrm{U}$ is crucially a linguistic utterance rather than an abstract proposition."

(16) a. He didn't call the [POlis], he called the [poLIS].

b. I didn't trap two monGEESE - I trapped two mongooses.

c. (- Esker too ah cooPAY luh veeAND?)

- Non, je n'ai pas 'cooPAY luh veeAND': j’ai coupé la viande.

(17) a. You didn't eat some of the cookies, you ate $\underline{\text { all }}$ of them.

b. It isn't possible she'll win, it's downright certain she will.

c. John isn't patriotic or quixotic, he's both patriotic and quixotic.

d. I'm not happy - I'm ecstatic.

e. It's not $\underline{\text { warm }}$ out; it's downright $\underline{\text { hot }}$.

\subsection{Problems with the neo-Gricean account of numerals}

In spite of its general appeal, the neo-Gricean view of numerals has not been immune to criticism. As Carston (1998, p. 197) observes, the following example from Harnish (1976) raises some serious problems for the neo-Gricean account:

... suppose you bet me that there will be 20 people at the talk tonight. We arrive and there are 25 people there. Who wins? There may be some temptation in both directions, but that seems to be because the question is underdetermined. It seems that the sentence

(32) There will be 20 people there.

can be used to make the following claims:

(33) a. There will be at most 20 people there.

b. There will be exactly 20 people there.

c. There will be at least 20 people there.

Of course, I do not want to claim that (32) is ambiguous and has (33) as its senses. Suppose that in the situation imagined, I had been complaining about the poor 
attendance at talks and you reply with (32) - against the mutual understanding that 20 people is a good turnout. In this context, what you said could have been paraphrased as (33c), and so you would win the bet. Another context could have changed the force of my utterance to either of the other two. (p. 326)

According to Carston (1998) the above example highlights two important problems for the traditional, neo-Gricean view of numerals. The first one is that the 'at most' reading, i.e. (33a), has largely been ignored by proponents of the neo-Gricean view. More importantly, however, it is hard to see how such an interpretation could be derived from an underlying 'at least' semantics. This so-called 'scale reversal' effect, originally noted by Horn (1972), was shown by Sadock (1984) not to extend to the other inexact scalar terms thereby setting numerals aside from other scalar terms. The examples below are from Sadock (1984, p. 143).

(18) a. That Golfer is capable of a round of 100 (and maybe even 90/*110).

b. She can counter most of the arguments (and maybe even *some/all).

The second problem revealed by Harnish's example is that, on a given occasion, the relevant interpretation of numerals, i.e. $(33 a-c)$, is taken to be explicitly communicated and not merely implicated - and thus to represent the truth conditional content of the utterance. The following examples, by Sadock (1984), illustrate this point. Sadock observes that the neo-Gricean view of numerals fails when applied to mathematical statements such as $2+2=3$ and The square root of 9 is 2 , both of which are predicted to be true on the 'at least' reading of numerals. Richardson and Richardson (1990, p. 501) further show that Sadock's example cannot be dismissed as a mere technicality, involving the mathematical use of number terms, by providing the following "perfectly colloquial and clearly quantificational sentence beyond the semantic reach of Horn [1972, 1989]'s proposal":

(19) I took six cigarettes with me, gave one to Fred and two to Ed, so I still have three.

Notice here that an 'exact' interpretation achieved by adding an implicated upper-bound to an 'at least n' semantics would yield the wrong truth conditions for (19). Thus, the upperbound cannot be merely implicated; it must be part of the truth conditional content of the utterance.

These, and related problems, have led some investigators, including Horn himself (e.g. Horn, 1992), to abandon the neo-Gricean view of numerals, even though they still believe that this account represents the correct analysis for the inexact scalar terms (e.g. some, most, etc.). (However, see Levinson (2000) for a recent defense of the neoGricean view). A recent alternative to the neo-Gricean approach maintains that numerals are semantically underspecified in the sense that they do not directly encode the 'at least n', 'exactly n' or 'at most n' readings. On this view, a particular interpretation for a numerally quantified NP arises through a process of 'pragmatic enrichment' (Atlas, 1990; Carston, 1985; Horn, 1992 among others). Carston (1985) proposes that the semantic representation of numerals, say two for example, should be conceived as shown in (20). 


\section{(20) $[\mathrm{X}[\mathrm{two}]]$}

On this analysis, the representation in (20) requires that the variable ' $X$ ' be instantiated through a process of pragmatic enrichment signaled in the logical form of the utterance. In other words, contextual information will fix the value of the expression in (20) as either 'at least two', 'at most two' or 'exactly two' depending on the particular occasion of use.

Koenig (1991) proposes another alternative to the neo-Gricean view. Instead of building the interval, i.e. 'at least $n$ ' interpretation into the lexical semantics of numerals and deriving the exact semantics pragmatically, Koenig propose the exact opposite, namely that numerals have a punctual lexical semantics and that they only sometimes acquire an interval semantics. Koenig's account relies on the observation that numerals can either give rise to a distributed or to a set reading. So for example, (21) can be paraphrased either as (22) or (23).

(21) Three boys carried a sofa up the stairs.

(22) There is a set M, M a set of boys of cardinality 3, for each boy b in M, b carried a sofa up the stairs.

(23) There is a set M, M a set of boys of cardinality 3, M carried a sofa up the stairs.

Koenig further observes that only distributed readings of numerals, i.e. (22), give rise to scalar entailment, as shown by the examples in (24).

(24) a. Mary didn't see three men. $\Rightarrow$ Mary didn't see four men.

b. Three men didn't come. $\Rightarrow$ Four men didn't come.

c. Mary saw three men. $\Rightarrow$ Mary saw two men.

d. Three men came. $\Rightarrow$ Two men came.

e. Three boys together didn't carry a sofa up the stairs. ( $\Rightarrow$ Four boys together didn't carry a sofa up the stairs.

f. Three boys together brought a sofa up the stairs. ( $\Rightarrow$ Two boys together brought a sofa up the stairs.

Rather than proposing that numerals have an interval, i.e. at least semantics and being left with the task of explaining why they do not give rise to scalar effects on their set interpretation, Koenig (1991) proposes that numerals have a punctual, i.e. exact semantics and that their scalar effects, when they are interpreted distributively, receive a straightforward explanation: "If there is a set of three members such that Mary saw each member, there is obviously a set of two members such that Mary saw each of them ... Similarly, the aforementioned scale reversal effect of negation is directly accounted for. If there is no set of cardinality three such that Mary saw each of its members, a fortiori there is no set of cardinality four such that Mary saw each of its members." (p. 147). On this view, scalar effects do not arise when numerals receive a set interpretation simply because the fact that a property is true of a set of cardinality $\mathrm{N}$ does not entail that it is also true of a set of cardinality $\mathrm{M}<\mathrm{N}$. 


\section{Developmental background}

Since G\&G's seminal study, an impressive amount of research has been conducted on children's growing conceptions of number. There is good evidence that by the age of 3, young children can count rows of up to five objects by reciting the number sequence while pointing at each object (Fuson, 1988; Gelman \& Gallistel, 1978; Wynn, 1992). However, children of this age do not seem to have a very solid grasp of the fact that counting can be used as a way to determine the cardinality of a set (what G\&G called the cardinal principle). The evidence comes from the behavior of children in a number of related tasks. For example, when asked to count a row of objects and then asked how many objects there are, many 3-year-olds do not respond with the last count word. They may say a different count word or count the row again (Fuson, 1988; Wynn, 1990; but see Gelman, 1993). Nor do children of this age spontaneously engage in counting when the problem they are asked to solve clearly requires it (Michie, 1984; Mix, 1999) or use counting to generate sets, as when they are asked to give an experimenter a specific number of objects (Wynn, 1990).

These findings have led to different views on children's early apprehension of the meaning of number words. Sarnecka and Gelman (in press) discuss two recent hypotheses regarding children's understanding of number words whose exact meaning they haven't yet figured out. According to what Sarnecka and Gelman call the Specific/Unique Numerosities (SUN) view, proposed by Karen Wynn (Bloom \& Wynn, 1997; Wynn, 1992), children contrast the meaning of known and unknown number words "because they know that each number word must correspond to a specific, unique numerosity, even before they know which word refers to which numerosity" (Sarnecka \& Gelman, in press). By contrast, Carey (2001) and Spelke and Tsivkin (2001) propose that children initially treat all numbers above 3 or 4 to mean essentially the same thing, i.e. something like many or $a$ lot. In other words, children do not initially have access to large, exact numerosities. This only happens as a result of the integration of two conceptual systems, via language. The first system enables infants to apprehend small, exact numerosities (Starkey \& Cooper, 1980; Strauss \& Curtis, 1981; Van Loosbroek \& Smitsman, 1990) and the other enables them to grasp large, approximate numerosties (Xu \& Spelke, 2000). This is what Sarnecka and Gelman call the Approximate Numerosities/Bootstrapping (ANB) view which they describe as follows: "According to this view, children do not think about large, exact numerosities until an understanding of cardinality and the linguistic counting system makes such abstraction readily available (Carey, 2001). Thus the linguistic technology allows children to "bootstrap" representations of integers, which were inconceivable before." (Sarnecka \& Gelman, in press). However, see Grinstead, MacSwan, Curtiss, and Gelman (1998) for evidence supporting the independence of language and number and also see Gelman and Cordes (2001).

In spite of differences in opinion over exactly when and how children learn the meaning of number words, all developmental accounts seem to agree on at least two things. The first is that by the age of 4 and a half or 5 children have mastered the basics of the counting system and therefore know the meanings of the number words above 3 or 4 . The second is that learning the meaning of number words amounts to figuring out that they refer to "specific, unique numerosities" to use Sarnecka and Gelman's phrasing (when these words 
are used as quantificational determiners, of course). In fact, this assumption seems to be part and parcel of every account of the acquisition of the number vocabulary, as can be gathered from the quotes below.

in particular, children's earliest knowledge of number word meaning - that such words correspond to precise numbers - ... (Bloom, 2000, p. 221)

Findings support the hypothesis that children view number words as denoting specific, unique numerosities ... (Sarnecka \& Gelman, in press)

In other words, children knew that "three" referred to a numerical set that was not "two", even if they did not know the exact referent. (Mix, Huttenlocher, \& Levine, 2002, p. 103)

As the work of theoretical linguists demonstrates however (see Section 2), knowledge of the meaning of number words extends far beyond the realization that phrases like three dogs typically refer to three-membered sets of dogs. Such expressions can, in addition to their 'exactly n' interpretation, receive an 'at least n' and an 'at most n' interpretation in specific contexts. Moreover, as discussed in Section 2, numerals interact with logical operators such as negation in non-trivial ways (see Lidz \& Musolino, 2002 for developmental evidence) and give rise to a range of entailment patterns and pragmatics effects. Thus, children's knowledge of the meaning of number words cannot be fully assessed until we learn more about their grasp of the facts discussed in Section 2.

It is interesting to observe in this regard that in spite of the considerable body of work currently available on the development of pragmatic abilities and the acquisition of the number vocabulary, phenomena such as scalar implicature and their relation to the semantics/pragmatics of numerals have barely received any developmental attention (but see Chierchia, Crain, Guasti, Gualmini, \& Meroni, 2001; Gelman, 1993; Noveck, 2001). To my knowledge, only one study so far, by Papafragou and Musolino (2003) (henceforth P\&M), has considered children's interpretation of numerally quantified NPs in the context of the framework discussed in Section 2. P\&M's study therefore constitutes a natural starting point for the present investigation.

P\&M's study grows out of the recent observation that preschoolers, who are otherwise semantically competent, often show a remarkable lack of sensitivity vis-à-vis scalar implicatures in tasks designed to assess language comprehension (Chierchia et al., 2001; Musolino \& Lidz, 2002; Noveck, 2001; Papafragou \& Musolino, 2003). The generalization emerging from this recent line of research is that although adults tend to favor the pragmatic interpretation of weak scalar terms (e.g. some as being incompatible with $a l l$ ), young children often interpret the same terms semantically (e.g. some as being compatible with all).

Inspired by this general observation, and curious to determine its scope and origin, P\&M tested preschoolers and adults on a broader range of scales, including a numerical one. Specifically, P\&M considered quantificational scales (i.e. some, all), numerical scales 
(i.e. two, three) and aspectual scales (i.e. start, finish) ${ }^{6}$ In each case, the weaker terms on the scales, i.e. some, two, start, were used to describe situations which satisfied the truth conditions associated with the stronger terms on the respective scales, i.e. all, three, finish. So, for example, in the scenario corresponding to the quantificational and numerical scales, three horses considered jumping over a fence and all three of them managed to jump over it. At the end of the story, a puppet described what happened by saying that some/two of the horses jumped over the fence. In this case, a pragmatically savvy participant should object to the puppet's statements on the grounds that all the horses jumped, in the quantificational case, and that three of the horses jumped, in the numerical case. In the aspectual case, one of the scenarios involved a character trying to make a puzzle. At the end of the story, in spite of the fact that the character had successfully put the puzzle together, the puppet described the situation by saying that "[The character] started making the puzzle". Here again, one would expect a pragmatically competent participant to object to the puppet's statement on the grounds that the character did not just start making the puzzle, but in fact finished it.

What P\&M found is that while adult participants overwhelmingly rejected the puppet's statements in all three conditions (i.e. quantificational, numerical and aspectual), 5-yearolds almost never did so on the quantificational and aspectual scales. In other words, as in previous studies, preschoolers almost always interpreted some and start semantically, i.e. as compatible with all and finish. The surprising result came from children's behavior on the numerical scale. Instead of treating two as compatible with three, children consistently rejected the puppet's statements. That is, children objected to the puppet's statement that "two of the horses jumped over the fence" on the grounds that three horses - and not just two - had jumped over the fence.

While P\&M's findings clearly demonstrate that preschoolers treat numerals differently from other scalar terms, these results nevertheless remain open to at least two interpretations. The first one would be (a) that children and adults have the same semantic representation for numerals and (b) that this representation does not correspond to an 'at least n', neo-Gricean semantics. On the assumption that (a) holds, the conclusion in (b) follows from the reasoning that if the neo-Gricean analysis of numerals were correct, implicature-insensitive children would be expected to treat both some and two as compatible with stronger values on their respective scales, i.e. all and three. Crucially, however, $\mathrm{P} \& \mathrm{M}$ showed that this prediction is not born out - hence the conclusion in (b). Under this set of assumptions, P\&M's results would further entail that the correct analysis of numerals in the adult grammar cannot correspond to an 'at least n' semantics, because of the equivalence between the child and the adult system stated in (a). Thus, on this scenario, P\&M's results would not only have implications for children's representation of numerals but also for the correct analysis of numerals in the adult grammar. Let us call this option 1.

Notice now that the implications of P\&M's results vis-à-vis the correct analysis of numerals in the adult grammar crucially rest on the validity of premise (a) above, namely

\footnotetext{
${ }^{6}$ In fact, P\&M tested speakers of Modern Greek. For ease of exposure, however, I will use English examples. Due to the universal nature of scalar implicatures, the fact that Greek was used instead of English has no bearing on the arguments presented here.
} 
the equivalence between the semantic representations of children and those of adults. However, there is nothing about P\&M's findings which guarantees that this equivalence must hold. To be sure, the following scenario, option 2 , would be perfectly compatible with P\&M's findings: (a) children and adults have a different semantic representation for numerals (contrary to (a) under option 1); (b) the adult representation of numerals corresponds to an 'at least n', neo-Gricean semantics; and (c) children initially assign numerals an 'exactly n' semantics and they do not yet have access to the pragmatic mechanisms which yield interval interpretations ('at least/most n') from an underlying 'exactly n' semantics (see Section 2.3). This, in turn, would lead to the prediction that children should always assign numerals an 'exactly n' interpretation, even in contexts in which adults would otherwise prefer an 'at least n' or 'at most n' interpretation. Moreover, this would be perfectly compatible with children's behavior in P\&M's study, i.e. their tendency to access the 'exactly n' reading of the numerals.

Thus, rather than placing the burden of explanation on the theorist concerned with a proper characterization of the adult system (under option 1), P\&M's results (under option 2) could as easily be construed as placing the burden of explanation on the developmentalist who would have to explain why and how a child starting with a nonadult semantic representation - along with certain pragmatic limitations (i.e. (c) under option 2) - would at some point experience a neo-Gricean epiphany. Certainly, parsimony and continuity could be invoked, but the question of whether preschoolers' semantic representation of numerals initially differs from that of adults remains an empirical one.

The upshot of these deliberations is that the implications of P\&M's results for the correct semantic analysis of numerals in the adult grammar cannot be properly evaluated until we can decide which of the two options described above is the correct one. This, in turn, boils down to whether children do or do not have access to the 'at least/most n' interpretation of numerals. To the extent that the answer to this question is positive, the main prediction of option 2 would be falsified. In other words, such a result would show that children can assign the full range of interpretations available in the adult grammar. This, in turn, would be tantamount to showing that children and adults have the same semantic representations for numerals, which corresponds to premise (a) of option 1 . Once the validity of this premise is established, the incompatibility of P\&M's results with the neo-Gricean analysis of numerals would follow, for both child and adult grammar. Our first experimental task, therefore, is to determine whether 5-year-olds can assign numerically quantified expressions non-exact interpretations, i.e. 'at least n' and 'at most n'.

\section{Experiment 1}

The purpose of this experiment is two-fold. First, it seeks to verify that adult speakers of English do assign numerally quantified NPs 'non-exact' interpretations, i.e. 'at least n' and 'at most n', in the relevant contexts. To the extent that this is the case, I then ask whether 5-year-olds can do the same. Accordingly, my research strategy was to create contexts in which numerally quantified NPs would most naturally receive 'at least/most n' interpretations. This was achieved by using numerals to describe the performance of a character involved in a game or a competitive activity. 
Imagine for example that you were given five hoops and told that you had to put two on a pole in order to win a prize. In this situation, a statement such as you need to get two hoops on the pole in order to win should be naturally interpreted as you need to get at least two hoops on the pole to win. In other words, getting more than two hoops on the pole still guarantees a win. Suppose now that you were told that you could miss two hoops and still win the prize. Here, two hoops is most naturally interpreted as at most two hoops. That is, missing only one hoop should still allow you to win.

\subsection{Method}

\subsubsection{Subjects}

We tested 20 English-speaking children (12 girls and 8 boys) between the ages of 4;3 and $5 ; 11$ (mean $5 ; 1$ ). We chose children in that age range to make sure that our results could be compared to those obtained by $\mathrm{P} \& \mathrm{M}$. The children were recruited at preschools in the Bloomington area. Five children were replaced in the design because they were either too shy or because they couldn't provide any justification to their answers. We also tested a control group of 20 adult native speakers of English, all undergraduate students at Indiana University.

\subsubsection{Procedure}

We tested subjects' interpretations of sentences containing numerally quantified NPs using the Truth Value Judgment Task methodology (TVJT) (Crain \& Thornton, 1998). The TVJT typically involves two experimenters. The first experimenter acts out short stories in front of the subjects using small toys and props. The second experimenter plays the role of a puppet (in this case Elmo) who watches the stories alongside the subjects. At the end of the story, the puppet makes a statement about what he thinks happened in the story. The subjects' role is to determine whether the puppet's statement is 'right' or 'wrong'. Finally, subjects are asked to justify their answers by explaining why they think that the puppet is right or wrong. Alternatively, the puppet may ask subjects a question about the story in which case they are expected to answer the puppet's question. Here too, subjects are asked to provide justifications for their answers. For a more detailed discussion of the TVJT, see Crain and Thornton (1998).

It should be noted at this point that there is by now overwhelming evidence that children as young as 3;5 or even 3;0 - and certainly 4- and 5-year-olds - experience no difficulty whatsoever with the TVJT and that they are perfectly capable of giving either 'yes' or 'no' answers when appropriate, including appropriate justifications for their answers. The TVJT has now been used successfully to test children's knowledge of complex linguistic constructions in a variety of languages, including English (Crain \& Thornton, 1998; Musolino, Crain, \& Thornton, 2000), Greek (Papafragou \& Musolino, 2003) and Kannada (Dravidian) (Lidz, \& Musolino, 2002).

The children were first introduced to the task as a group and then tested individually in a quiet room away from the class. Each child received two pretest stories and if they could answer those appropriately (including appropriate justifications for their answers), they would then hear eight more stories: four test stories and four control stories, administered in a pseudo-random order. 
Adult subjects were shown a videotaped version of the stories witnessed by the children, including the pretest stories. They were given a score sheet and were instructed to indicate, for each story, how they would answer the puppet's questions, i.e. 'yes' or 'no'. They were also asked to provide justifications for their answers.

\subsubsection{Materials}

The experiment had two conditions: one designed to test subjects' ability to access the 'at least n' interpretation of numerals ('at least' condition) and the other designed to test their ability to access the 'at most n' interpretation ('at most' condition). In the 'at least' condition, subjects were tested on their interpretation of statement/question pairs like (25).

(25) Goofy said that the Troll had to put two hoops on the pole in order to win the coin. Does the Troll win the coin?

In the story corresponding to (25), for example, Goofy has a beautiful coin and the Troll asks what it would take for Goofy to give him the coin. Goofy points to some hoops and a pole. He then tells the Troll that he has to throw the hoops at the pole and that he has to get two hoops on the pole in order to win the coin. There is a total of five hoops and after throwing each of them, the Troll misses one shot but manages to get the other four hoops on the pole (see Fig. 1).

At this end of the story, the puppet uses the statement/question pair in (25), i.e. "Well, Goofy said that the Troll had to put two hoops on the pole in order to win the coin. Does the Troll win the coin?". Notice that if two hoops in (25) is interpreted as 'at least two hoops', i.e. two hoops or more, then the answer to the puppet's question should be 'yes', since the Troll did get at least two hoops on the pole. On the other hand, if two hoops is interpreted as 'exactly two hoops', then the answer to the puppet's question should be 'no' since

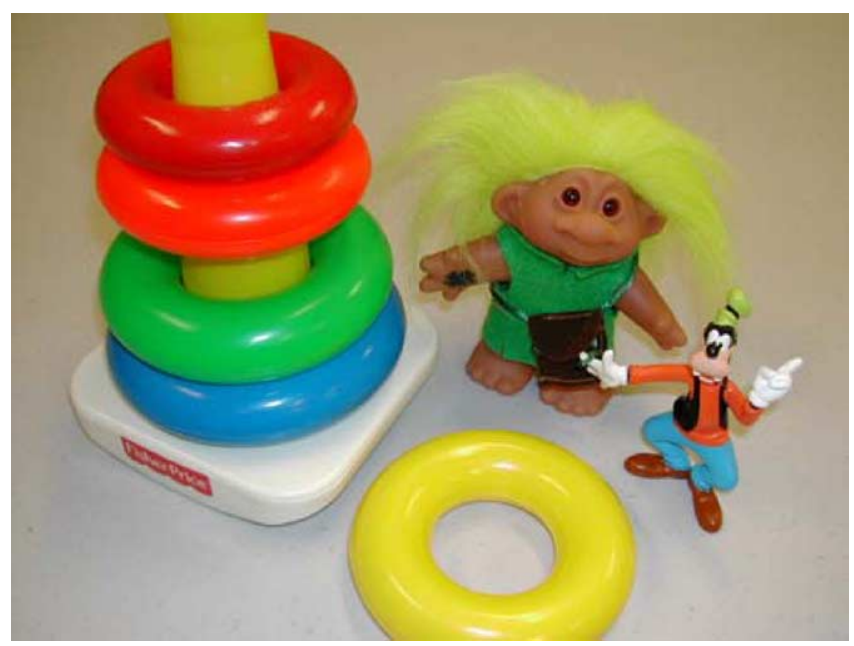

Fig. 1. Goofy said that the Troll had to put two hoops on the pole to win. Does the Troll win? 
Table 1

The puppet's statements/questions on test stories, 'at least' condition

Test story 1 Goofy said that the Troll had to put two hoops on the pole in order to win the coin. Does the Troll win the coin?

Test story 2 Pink Panther said that if the horse made it over two obstacles he would win. Does the horse win the blue ribbon?

Test story 3 Mickey said that if Cookie Monster got two basketballs in the net he would get the donut. Does Cookie Monster get Mickey's donut?

Test story 4 Smurfette said that if Carpenter Smurf knocked down two pins she would give him her flower. Does Carpenter Smurf get Smurfette's flower?

the Troll didn't get exactly two hoops on the pole. The puppet's statements/question pairs on each test trial are given in Table 1.

In the 'at most' condition, subjects were asked to respond to statement/question pairs like (26).

(26) Goofy said the Troll could miss two hoops and still win the coin. Does the Troll win the coin?

For the sake of comparison, the stories used in the 'at most' condition were only minimally different from the ones used in the 'at least' condition. In the story corresponding to (26) for example, Goofy has a beautiful coin and the Troll asks what he could do to get it. Goofy points to some hoops and a pole. He then tells the Troll that he has to throw the hoops at the pole and that he can miss two shots and still win the coin. There are five hoops and the Troll only misses one shot. In other words, he gets four hoops on the pole.

At the end of the story, the puppet uses the statement/question pair in (26), i.e. "Well, Goofy said that the Troll could miss two hoops and still win the coin. Does the Troll win the coin?". Notice that if two hoops in (26) is interpreted as 'at most two hoops', then the Troll should win the coin since he missed only one hoop. On the other hand, if two hoops is interpreted as 'exactly two hoops', then the Troll doesn't win the coin since the number of hoops that he missed is different from two. The puppet's statement/question pairs on each test trial are given in Table 2.

In addition to the four test stories, children in each condition also heard four control stories. Overall, the control stories were designed to ensure that children in that age range do not experience any difficulty with conditional statements, i.e. so and so wins if such and such happens. The statement/question pairs used by the puppet on control stories, unlike

Table 2

The puppet's statements on test stories, 'at most' condition

Test story 1 Goofy said the Troll could miss two hoops and still win the coin. Does the Troll win the coin?

Test story 2 Pink Panther said the horse could knock down two obstacles and still win the blue ribbon. Does the horse win the blue ribbon?

Test story 3 Mickey said that Cookie Monster could miss two shots and still get the donut. Does Cookie Monster get Mickey's donut?

Test story 4 Smurfette said that Carpenter Smurf could miss two pins and still get her flower. Does he get Smurfette's flower? 
Table 3

The puppet's statements on control stories, 'at least' and 'at most' conditions

Control story 1 The girl told her brother that if he could push the car through the cones without knocking any down he would give her the giant milkshake. Does he win?

Control story 2 The man said that the pirate had to get the green block on the table to win. Does the pirate win the ring?

Control story 3 The cat said that the dog had to catch the blue frog to get the piece of chicken. Does the dog get the piece of chicken?

Control story 4 Goofy told Donald that he had to find Mickey to win. Does Donald win the car?

the ones used in test stories, were not ambiguous. Moreover, the experimenter holding the puppet had a choice between two different outcomes for each story. One outcome was designed to satisfy the truth conditions of the puppet's question, and therefore elicit a 'yes' answer. The alternative outcome, which did not satisfy the truth conditions of the puppet's question, was designed to elicit a 'no' answer.

If a child had answered 'yes' to a given test story, the experimenter holding the puppet was instructed to pick the outcome for the following control story corresponding to a 'no' answer, and vice-versa. This precaution was taken to ensure that the number of 'yes' and 'no' answers was balanced and that children could provide either a 'yes' or a 'no' answer when appropriate. The puppet's statements/questions on the control stories are given in Table 3.

Finally, the 40 subjects (20 children and 20 adults) were randomly assigned to each condition yielding a $2 \times 2$ design with age (children vs. adults) and context (i.e. 'at least' vs. 'at most') as between subjects factors and ten subjects per cell. The group of ten children ( 6 girls and 4 boys) assigned to the 'at least' condition ranged in age from $4 ; 3$ to $5 ; 11$ (mean $5 ; 1)$ and the ten children ( 6 girls and 4 boys) assigned to the 'at most' condition ranged in age from $4 ; 3$ to $5 ; 10$ (mean $5 ; 1$ ).

\subsection{Results}

In the analysis below, our dependent measure was the proportion of 'yes' responses to the puppet's questions. Beginning with test trials, we found that adults accepted the puppet's statements $95 \%$ of the time in the 'at least' condition and $97.5 \%$ of the time in the 'at most' condition. No reliable differences were found between these two means $(t(18)=0.44, P=0.66)$. By contrast, we found that while children accepted the puppet's statements $82.5 \%$ of the time in the 'at most' condition, they did so reliably less often in the 'at least' condition, i.e. $35 \%$ of the time $(t(18)=2.6, P=0.01)$.

The proportion of 'yes' responses was entered into a 2 (children vs. adults) $\times 2$ (at least vs. at most) analysis of variance (ANOVA) (see Fig. 2). The analysis revealed a significant main effect of age $(F(1,36)=15.8, P<0.001)$, a significant main effect of condition $(F(1,36)=7.0, P<0.01)$ and a significant interaction between age and condition $(F(1,36)=5.7, P=0.02)$.

On control items, children gave correct responses $97.3 \%$ of the time in the 'at least' condition and $97.5 \%$ of the time in the 'at most' condition. Children's near perfect 


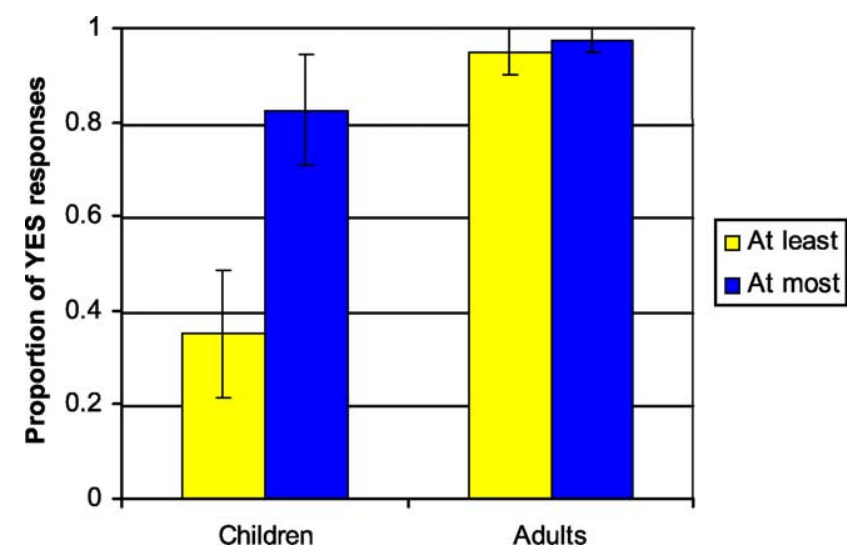

Fig. 2. Proportions of 'yes' responses to the puppet's statements in 'at least' and 'at most' conditions.

performance on control items clearly shows that they did not experience any difficulty with the task in general or with conditional statements in particular. Adults gave correct answers $100 \%$ of the time in both conditions.

Let us now turn to subjects' justifications. Beginning with adults, we found that in the 'at least' condition, when subjects answered the puppet's questions affirmatively (95\% of the time), they always invoked the fact that the characters in question had exceeded the minimum requirement, and so that they should win. Interestingly, a few subjects even explicitly stated that the characters should win because they had "put at least two hoops on the pole" or "thrown at least two basketballs in the net". The negative answers, accounting for 5\% of the total answers, came from one subject who on two of the four test trials explained that the character in question shouldn't win, by invoking the fact that the 'exact' interpretation of the numeral was false. In the 'at most' condition, adults always justified their affirmative answers by explaining that the main character had "only Ved one of the Ns".

Turning to children's justifications, we found that in the 'at least' condition, when children answered the puppet's questions affirmatively (only $35 \%$ of the time), they always explained, just like adults, that the main character should win because s/he had exceeded the minimum requirement, e.g. "The Troll had to get two hoops on the pole and he got four. So he wins." When children decided that the main character shouldn't win ( $65 \%$ of the time), they always invoked the fact that the 'exact' interpretation of the numeral was false. Interestingly, some children used the following construction to justify their negative answers: NP didn't V two Ns (PP). Note that whether they answered the puppet's question affirmatively or negatively, the children were always able to remember the number of objects on which the main character had to perform the action, i.e. two. Finally, in the 'at most' condition, when children judged that the main character should win $(82.5 \%$ of the time), they explained, just like adults, that the character in question had "only Ved one of the Ns". By contrast, when children decided that the main character shouldn't win (17.5\% of the time), they invoked the fact that the 'exact' interpretation of the numeral was false. 


\subsection{Discussion}

The first conclusion to be drawn from Experiment 1 is that adult speakers of English can easily access the 'at least n' and 'at most $n$ ' interpretation of numerals in contexts in which these interpretations are licensed $(95 \%$ and $97.5 \%$ acceptance rate, respectively, along with appropriate justifications). By contrast, we found that preschoolers' ability to access such interpretations is more fragile. Recall that although children could easily access the 'at most' reading of numerals, they had much more difficulty with the 'at least' interpretation ( $82.5 \%$ vs. $35 \%$ acceptance rate, respectively, $P=0.01)$. In the 'at least' condition, children displayed a strong tendency to assign the numerals an 'exact' interpretation ( $65 \%$ of the time, including appropriate justifications). These facts suggest that although preschoolers are not limited to the 'exactly n' interpretation of numerals (as witnessed by their behavior in the 'at most' condition), their ability to assign such expressions a 'non-exact' interpretation is nevertheless more fragile than that of adults (as witnessed by their behavior in the 'at least' condition).

Given the fact that preschoolers can, under certain circumstances, assign numerals a 'non-exact' interpretation (i.e. 'at most n'), one may wonder why they seem so reluctant to assign them an 'at least n' interpretation. As always in such cases, two kinds of explanations are possible. One is that children's difficulty with the 'at least n' interpretation reflects an underlying lack of knowledge. Perhaps children's grammars cannot yet generate the full set of interpretations available in the adult grammar. Alternatively, children and adults may share the same underlying grammatical knowledge but differ in the way they implement their knowledge.

To be sure, contextual factors and other task related demands have often been found to interfere with children's ability to put their grammatical knowledge to use (Crain \& Thornton, 1998; Gualmini, 2003; Musolino \& Lidz, 2002; Papafragou \& Musolino, 2003). As Gelman and Meck (1983) remind us “... theories of cognitive development [must] distinguish between implicit principles of knowledge and skills that derive from and/or are related to these principles. It will not do to base accounts of knowledge on a requirement that skills which reflect that knowledge be executed without error. Errors due to performance demands are to be expected."

The standard approach in such cases is to try to cancel the effect of these interfering factors by manipulating certain features of the context or the task. To the extent that such manipulations give rise to improved performance, explanations based on an underlying lack of knowledge are usually rejected. To quote Gelman and Meck (1983) again: "By contrasting performance on easy tasks ... and hard tasks ... we hoped to show that performance problems and not faulty principles explain many of the errors ..." (p. 345).

Following this line of reasoning, I begin by identifying a number of differences between the 'at least' and 'at most' conditions susceptible of yielding the asymmetry observed above. I then present the results of a new experiment designed to control for the potential effect of these extraneous variables and hence tease apart the 'lack of knowledge' and 'implementation' accounts of children's difficulty with the 'at least n' interpretation of numerally quantified NPs.

Although every effort was made to minimize differences between the 'at least' and 'at most' conditions, certain differences nevertheless inevitably remain, which, individually 
or collectively, may have contributed to the asymmetry discussed above. First, one might notice that the statements participants had to evaluate in each condition differed in the choice of linguistic expressions used to convey the conditions under which the character would win. In the 'at least' condition predicates such as have to, e.g. Goofy said that the Troll had to put two hoops on the pole in order to win the coin, and conditionals of the form if ... (then), e.g. Mickey said that if Cookie Monster got two basketballs in the net he would get the donut, were used. By contrast, the requirements in the 'at most' condition were all expressed by means of the modal could, e.g. Goofy said the Troll could miss two hoops and still win the coin. On the assumption that children differ in their command of these linguistic expressions, one could therefore be tempted to conclude that the use of these different expressions contributed to the asymmetry between the two conditions. However, notice that expressions such as have to and if ... then were also used in the control stories. Children's near perfect performance on the controls indicates that they in fact did not experience any difficulty with such expressions. Therefore, the asymmetry observed between the 'at least' and 'at most' conditions is unlikely to be due to children's poor command of expressions like have to or if ... then.

Another difference between the two conditions concerns the point at which one can reliably infer that the character has fulfilled the condition required to win. Notice that in the 'at least' condition, the character needs in principle only perform the relevant action with respect to two members of the set of objects. So, for example, in the story involving a Troll throwing hoops at a pole, the Troll, who is given five hoops and told that he has to put two on the pole to win, could in principle stop throwing hoops after his second successful shot. However, this is not what happens in the story: after making two successful shots, the Troll continues to throw hoops at the pole (recall that the Troll ends up getting four hoops on the pole). Notice now that a similar situation arises in the 'at most' condition. The Troll could in principle stop throwing hoops after he made three successful shots. That is, even if the Troll misses the remaining two shots, he still wins. The difference between these two cases, however, is that it may be easier for a child to realize that the Troll has fulfilled the required expectation in the 'at least' condition. In order to do that, the child needs only consider the number of hoops that are on the pole. In the 'at most' condition, the reasoning that the child would have to go through is more complex in that it relies on a hypothetical situation: were the Troll to throw the last two hoops at the pole, and were he to miss both, he would then have only missed two shots, which does not exceed the limit. Notice that this reasoning holds, in both cases, regardless of which shots (i.e. the first, the second, etc.) the Troll misses. The upshot of these deliberations is that the point at which the character wins may be easier to perceive in the 'at least' condition. On the assumption that children find it odd that the character continues to perform the action beyond the winning point, this oddity should thus be more apparent in the 'at least' condition.

A third, related difference involves the fact that in the 'at least' condition, the character's performance has to be evaluated on the basis of what he scores (i.e. how many hoops were on the pole, how many basket balls in the net, etc.), whereas in the 'at most' condition, the evaluation is based on what the character missed. To the extent that the outcome of the games that preschoolers are familiar with more often relies on what someone scores, rather than on what someone fails to score, it is conceivable that in the context of a game, children would be pickier about keeping an accurate record of what gets 
scored as opposed to what is missed. If so, children may be biased towards an 'exactly n' interpretation in case they have to focus on what gets scored but they may have more 'flexible' standards in case the relevant measure is what someone missed.

In order to tease apart the 'competence'/'performance' accounts of children's difficulty with the 'at least n' interpretation of numerals, the research strategy I chose to follow aims at removing the effect of the potential factors identified above - by eliminating them altogether - while at the same time boosting the availability of the reading under consideration, i.e. 'at least n'. Experiment 2 describes how this was achieved.

\section{Experiment 2}

The goal of this experiment was to test preschoolers' interpretation of numerals in contexts which, for reasons discussed above, do not involve a game or competition as was the case in Experiment 1, but which nevertheless create a situation in which the most felicitous interpretation of a numeral would be an 'at least n' interpretation. In this regard, it has often been observed in the semantics/pragmatics literature that a typical 'at least n' context arises in situations like the ones described by Kadmon (2001):

For example, suppose I need to borrow four chairs for a meeting I have in my office. Then you can say (2) to me, and I am not going to understand that Leif has exactly four chairs.

(2) Leif has four chairs. (p. 68)

The intuition here is that the numeral is interpreted with respect to the person's needs and that as long as four chairs are enough to satisfy this need, the number of additional chairs owned by Leif - and hence the exact number of chairs that Leif owns - becomes irrelevant.

Based on this intuition, I developed stories in which one of the characters needed to borrow or obtain a specific number of items (i.e. two items) from another character who owned more that the required number, e.g. three, four, etc. One story, for example, involved Goofy, who was selling cookies, and a Troll. The Troll was expecting a friend to come over to his house and so he bought one cookie from Goofy. In the end, the Troll's friend brought two additional friends along with him. The Troll said that he was pleased to see all three of them but that he had bought only one cookie. The Troll went back to Goofy to see if he could buy two more cookies. Goofy, who started with four cookies, now has three left (see Fig. 3). At this point, the puppet makes the statement and asks the question in (27).

(27) Let's see if Goofy can help the Troll. The Troll needs two cookies. Does Goofy have two cookies?

Notice that if one interprets two cookies in (27) to mean exactly two cookies then the answer should be 'no' since Goofy has three cookies, not two. On the other hand, if one 


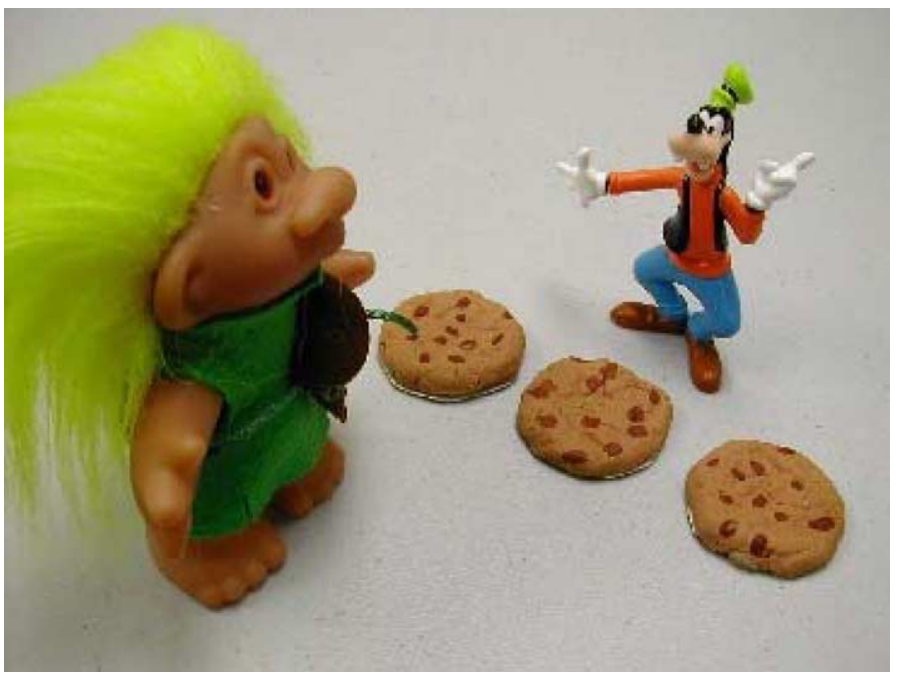

Fig. 3. Let's see if Goofy can help the Troll. The Troll needs two cookies. Does Goofy have two cookies?

were to interpret two cookies as at least two cookies, then the answer to the question should be 'yes' since Goofy does indeed have at least two cookies.

\subsection{Method}

\subsubsection{Subjects}

We tested 20 English-speaking children (10 girls and 10 boys) between the ages of $4 ; 4$ and 5;8 (mean 5;0). The children were recruited at daycare centers in the Bloomington area. Four children were replaced in the design because they were either too shy or because they couldn't provide any justifications to their answers. We also tested a control group of 20 adult native speakers of English, all students at Indiana University.

\subsubsection{Procedure and materials}

As in Experiment 1, we used the TVJT methodology. ${ }^{7}$ The experiment had two conditions. The first condition was designed to replicate the 'at least' condition of Experiment 1 and so we used the same materials as those used in Experiment 1. The second condition, called the 'improved context' condition, was based on the logic discussed and illustrated above. The complete list of critical statements/questions is given in Table 4.

\footnotetext{
${ }^{7}$ As a reviewer pointed out, Experiments 1 and 2 are not purely about 'truth conditions' but also involve pragmatics. Calling these experiments 'truth value judgment tasks' might therefore be confusing. The 'Truth Value Judgment Task' (TVJT), however, is just the name of the technique I used. However misleading the name of this technique may be in the present situation, it is clear that the TVJT can be used to assess knowledge of both semantics and pragmatics, as shown here.
} 
Table 4

The puppet's statements on test stories, 'at least' condition

\begin{tabular}{ll}
\hline Test story 1 & $\begin{array}{l}\text { Let's see if Goofy can help the Troll. The Troll needs two cookies. Does Goofy have two } \\
\text { cookies? }\end{array}$ \\
Test story 2 & $\begin{array}{l}\text { Let's see if Cookie Monster can help the man. The man needs two cars. Does Cookie Monster } \\
\text { have two cars? }\end{array}$ \\
Test story 3 & $\begin{array}{l}\text { Let's see if the man can help Pink Panther. Pink Panther needs two pumpkins. Does the man } \\
\text { have two pumpkins? }\end{array}$ \\
Test story 4 & $\begin{array}{l}\text { Let's see if Goofy can help Mulan. Mulan needs two bowling balls. Does Goofy have two } \\
\text { balling balls? }\end{array}$
\end{tabular}

In addition to the four test stories, children also heard four control stories. As before, the statements made by the puppet on the control stories were not ambiguous and the experimenter holding the puppet had a choice between two different outcomes for each of the control stories. The control stories were identical to the ones used in Experiment 1 and they were the same for the 'replication' and the 'improved context' conditions.

Finally, as in Experiment 1, the 40 subjects (20 adults and 20 children) were randomly assigned to each of the two conditions yielding a 2 (children vs. adults) $\times 2$ (replication vs. improved context) design and 10 subjects per cell. The group of 10 children $(5$ girls and 5 boys) assigned to the 'replication' condition ranged in age from $4 ; 5$ to $5 ; 6$ (mean $4 ; 11$ ) and the 10 children ( 5 girls and 5 boys) assigned to the 'improved context' condition ranged in age from $4 ; 4$ to 5;8 (mean 5;0). These two means did not differ significantly $(t(18)=-0.46, P=0.64)$.

\subsection{Results}

As before, our dependent measure was the proportion of 'yes' responses to the puppet statements. We found that children accepted the puppet's statements only $30 \%$ of the time in the replication condition - thereby replicating the results of Experiment 1 - but that they did so significantly more often, i.e. $80 \%$ of the time, in the 'improved context' condition $(t(18)=-2.46, P=0.02)$. Adults, on the other hand, almost always accepted the puppet statements, i.e. $97.5 \%$ of the time in the 'replication' condition and $100 \%$ of the time in the 'improved context' condition.

The proportion of 'yes' responses was entered into a 2 (children vs. adults) $\times 2$ ('replication' vs. 'improved context') ANOVA. The analysis revealed a significant main effect of age $(F(1,36)=18.34, P<0.0001)$, a significant main effect of context $(F(1,36)=6.6, P<0.01)$ and a significant interaction between age and context $(F(1,36)=5.4, P=0.02)$ (see Fig. 4$)$.

Turning to justifications, children in the 'replication' condition behaved just like the children in Experiment 1. In other words, they explained their negative answers by invoking the fact that the main character failed to $\mathrm{V}$ exactly two $\mathrm{N}$. In the 'improved context' condition, in which children's responses to the puppet's questions were overwhelmingly affirmative, we asked participants to show us why they thought the character in question had two Ns whereas s/he in fact had three. What children did in this 


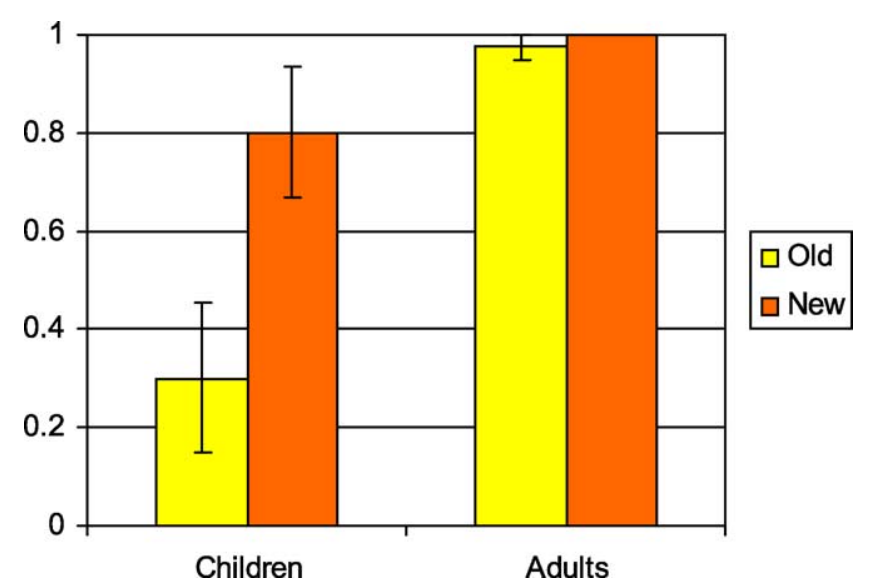

Fig. 4. Proportions of 'yes' responses to the puppet's statements in 'replication' (old) and 'improved context' (new) conditions.

case is get two of the three relevant objects (i.e. cookies, cars, etc.) and give them to the two characters who needed them.

\subsection{Discussion}

Beyond replicating the effect observed in Experiment 1, the results of Experiment 2 demonstrate that by the age of 5 children have implicit knowledge of the fact that numerically quantified NPs can receive an 'at least n' interpretation. We must therefore conclude that children's apparent difficulty with the 'at least $n$ ' reading, witnessed in Experiment 1 and replicated in Experiment 2, is due to difficulties in implementation rather than an underlying lack of knowledge. Note, however, that the results of Experiment 2 do not allow us to determine precisely why children experienced difficulty with the 'at least n' interpretation in the context described in Experiment 1. The answer to this question will have to await further investigation.

Combining the results of Experiments 1 and 2, we can now conclude that by age 5 children have implicit knowledge of the fact that numerally quantified NPs can receive 'non-exact' interpretations, i.e. 'at least n' and 'at most n', in certain contexts. What is remarkable about the results of Experiment 2 is that children are able to pragmatically adjust their interpretation of numerals. Recall that when asked a question such as Does Goofy have two cookies? in a context in which the cardinality of the set of cookies possessed by Goofy is three, children overwhelmingly answered 'yes' (as did adults), thereby showing that they can indeed interpret numerals 'pragmatically'.

The observation that preschoolers can adjust their interpretation of numerals as a function of the pragmatic situation in which they are used leads to another important question: can children do the same when numerals are modified explicitly? Notice that English provides lexical means to express the 'at least/most/exact' interpretation of numerals explicitly, as witnessed by the existence of such phrases as at least two cookies, 
at most two hours and exactly three dogs. Another reason to ask whether children know the meaning of expressions such as at least/most two $N$ has to do with a question arising from the results of Experiments 1 and 2, namely how do children learn that numerally quantified NPs such as two $N$ can receive 'non-exact' interpretations? Since English provides lexical means to explicitly encode such interpretations, it wouldn't be unreasonable to suppose that knowledge of the full range of interpretations available to expressions such as two $N$ may come through a prior understanding of the meaning of expressions such as at least/most two $\mathrm{N}$. Experiment 3 was designed to address these questions.

\section{Experiment 3}

\subsection{Method}

\subsubsection{Subjects}

We tested 16 English-speaking children ( 8 girls and 8 boys) between the ages of $4 ; 9$ and $5 ; 8$ (mean 5;2). Most of the children were recruited from the Prep School, a daycare center in the Bloomington area, and the others were brought by their parents to the Psycholinguistics Laboratory at Indiana University. The children recruited at the Prep School were also tested there; the others were tested in our lab. We chose children in that age range because Experiments 1 and 2 show that these children have implicit knowledge of the fact that numerally quantified NPs can receive 'non-exact' interpretations.

\subsubsection{Procedure}

The experimental technique we used is a modified version of the TVJT. In the technique we used here, children were introduced to a 'picky' puppet who only likes to collect and keep certain things. Subjects were then shown series of cards with various stickers on them, i.e. smiley faces, stars or flags. Crucially, the cards differed in the number of smiley faces, stars or flags on them. Children were then told that the puppet only likes to keep cards with exactly/at least/at most two Ns on them and they were asked, for each card, to tell the experimenter whether the puppet would want to keep that card.

\subsubsection{Materials}

We tested children in two different conditions, 'at least' and 'at most'. In both conditions, children were presented with two sets of six cards showing either stars or smiley faces. Each set of cards contained a card that showed zero, one, two, three, four or five smiley faces/stars. In both conditions, children were told of one of the two sets of cards that the 'picky' puppet only wanted to keep cards that had exactly two Ns on them. In the 'at least' condition children were told of the second set of cards that the picky puppet only wanted to keep cards that had 'at least two smiley faces' on them while in the 'at most' condition, they were told that the puppet only wanted to keep cards that had 'at most two smiley faces/stars' on them. Children were shown the cards one by one and then asked whether the puppet wanted to keep each card.

The cards were arranged in a pseudo-random order so that they didn't form an ordered ascending or descending sequence, e.g. zero, one, two, three ... or five, four, 
three ... The 16 children were randomly assigned to the 'at least' and 'at most' conditions. The group of 8 children assigned to the 'at least' condition ranged in age from $4 ; 10$ to $5 ; 8$ (mean $5 ; 2$ ) and was composed of 4 girls and 4 boys. The group of children assigned to the 'at most' condition ranged in age from 4;9 to 5;7 (mean 5;2) and was also composed of 4 girls and 4 boys. In each condition, trials were blocked so that children would first have to judge the six cards in the 'exact' series and then the six cards in the 'at least/most' series. Order of presentation was counterbalanced between subjects such that half of the subjects were given the exact series to judge first and then the 'at least/at most' series and vice-versa for the other half. Within each series ('at least', 'exact' and 'at most') the order of presentation of the cards was counterbalanced between subjects such that half of the subjects were presented with the cards in pseudo-random order $\mathrm{O}$ and the other half with the reverse of O. Finally, children were also asked to judge another series of six cards of which they were told that the puppet only wanted to keep cards that had more than two Ns. ${ }^{8}$ The set-up described above gave rise to a $2 \times 2$ design with age (children vs. adults) and condition (at least vs. at most) as between subjects factors. The 'exactly 2' condition was used as a control condition and thus treated as a within subjects factor.

\subsection{Results and discussion}

We found that in both conditions, adults provided correct answers $100 \%$ of the time in the 'exactly 2' series. In the 'at least 2' series, subjects also gave correct responses $100 \%$ of the time and they did so $95.5 \%$ of the time in the 'at most 2' series. Turning to children, we found that subjects gave correct answers $100 \%$ of the time in the 'exactly 2' series. In the 'at least 2' series, children gave correct responses $50 \%$ of the time and they did so $54.1 \%$ of the time in the 'at most 2' series. Finally, in the 'more than 2' series, children gave correct responses $88 \%$ of the time.

The proportions of correct responses were entered into a 2 (age: children vs. adults) $\times 2$ (condition: at least vs. at most) ANOVA. The analysis revealed a significant main effect of age $(F(1,28)=154.16, P<0.0001)$, no significant effect of condition $(F(1,28)=0.0001, P=0.99)$ and no significant interaction between age and condition $(F(1,28)=1.25, P=0.56)$. Further analysis revealed that children's performance in the 'at least 2' and 'at most 2' series, i.e. $50 \%$ and $54.1 \%$ correct, respectively, didn't differ significantly from chance performance $(P>0.5)$. In the 'more than 2 ' series, however, children performed significantly above chance, i.e. $88 \%$ correct responses $(P<0.001)$.

We also found, in the 'at least' series, that not one child gave the correct pattern of responses (see Table A1 in Appendix A). In fact, all eight children gave the same pattern of responses, the one corresponding to 'exactly 2' (see Table A2 in Appendix A). When

\footnotetext{
8 The need to test children on their interpretation of 'more than 2' became apparent only after the experiment had begun. Consequently, we were only able to obtain data for seven of the 18 children (four in the 'at least' condition and three in the 'at most' condition). We tested these children on the 'more than 2' series only after they had been tested on the other material. This step guarantees that children's performance on the 'more than 2' condition did not interfere with their performance on the other conditions.
} 
asked what they thought expressions like 'at least two smiley faces' meant or asked if they could show us with the cards, three of the eight children said they didn't know and the other five said that it meant 'only 2', 'you only get 2', 'only means 2', 'when you count to 2 ' and 'means only 2'. In the 'at most' series, we also found that none of the eight children we tested gave the correct response pattern (see Table A3 in Appendix A). Five of the eight children gave the response pattern corresponding to exactly 2 (see Table A2 in Appendix A). The three remaining children gave different patterns, none of which corresponded to the correct one. When asked what they thought phrases like 'at most two N' meant, two children said they didn't know, three said they thought it meant '2' or 'only 2', one child said s/he thought it meant 'higher', another one that it meant 'four' (in fact this child's response pattern is consistent with the child's justifications) and another one that it meant 'more than 2' (this child's response pattern, however, was inconsistent with his/her explanation) (see Table A4 in Appendix A). By contrast, children had no difficulty explaining what exactly 2 and more than 2 mean.

The results of Experiment 3 are rather straightforward: children know what exactly 2 and more than 2 mean but they are clueless about the meaning of phrases like at least/most 2. Notice that this result cannot be due to the fact that children disregard modifiers preceding numerals. This explanation would be inconsistent with children's performance with phrases like more than 2. The results of Experiment 3, when combined with those of Experiments 1 and 2, reveal another interesting fact about preschoolers' verbal competence in the domain of number. Children are much more likely to adjust their interpretation of numerally quantified expressions when the context dictates that they do so (see Experiments 1 and 2) than when numerals are overtly modified. Although this may simply mean that 5-year-olds haven't yet learned the meaning of the words least and most, it is very interesting to observe how reluctant they are to deviate from the 'exactly n' interpretation even when numerals are explicitly modified. After all, what else could modifiers signal in expressions like at gorp 2 (for someone who doesn't understand what least or most means)? Overall, in spite of the fact that preschoolers can, under certain circumstances, assign numerals 'non-exact' interpretations, we do see a tendency in children to gravitate around the 'exactly $n$ ' interpretation, as witnessed by their behavior in the 'at least' condition of Experiment 1 (and its replication in Experiment 2) as well as their unwillingness to adjust their interpretation in Experiment 3. In fact, as Levinson (2000, p. 90) points out, this observation seems to hold quite generally: “... Cruse (1986:69-70) points out, that by certain tests for the better establishment of one sense over another, the 'exactly' interpretations of the English number words are psychologically more salient than the 'at least' interpretations ...". Perhaps this is due to the fact that numerals are only very rarely used on their 'non-exact' interpretations (see Section 7 for further discussion).

\section{General discussion}

The purpose of this study was to bring together theoretical and developmental perspectives on numerally quantified NPs, and to show that when integrated, these perspectives inform each other in novel and, I hope, interesting ways. Before 
considering how this may be so, let us begin by summarizing our findings. This study asked what truth conditions are associated with the use of numerally quantified NPs, e.g. two hoops, as well as when and how children learn what these truth conditions are. Our main finding is that by the age of 5 children have implicit knowledge of the fact that such expressions can receive 'non-exact' interpretations, i.e. 'at least n' and 'at most n' in certain contexts, while they do not yet know the meaning of corresponding expressions such as at least/at most two hoops which convey these senses explicitly. Moreover, we found that although preschoolers' semantic competence does not differ from that of adults, children's ability to implement their knowledge is nevertheless more fragile.

Let us now consider the implications of these findings for theories of the semantics of numerals as well as for theories of the acquisition of the number vocabulary. Beginning with the former, it has been a long-standing and central goal of linguistic theory to construct models of grammar which aim at explanatory adequacy, i.e. models that are responsive to the demands of language acquisition (Chomsky, 1965). Hornstein and Lightfoot (1981) define the problem as follows: "We shall try to justify our explanations on the basis of the following three criteria:

(a) Coverage of empirical data, showing that a class of facts follows from the principles we hypothesize.

(b) Standards of simplicity and elegance, showing that the principles meet the usual general requirements of scientific theorizing.

(c) A demonstration that the principles contribute insight on the central problem of acquisition." (pp. 14-15)

These authors further explain that "Criterion (c), that explanatory principles should illuminate the nature of the acquisition process, has fundamental importance ... One might postulate a simple, elegant principle entailing a significant range of facts, which makes no psychological sense in terms of language acquisition" (p. 16).

In this regard, I believe that the results presented here provide us with an interesting opportunity to bring data from child language to bear on the formulation of grammatical theory. Recall from the discussion in Section 2 that an important question in the semantics/pragmatics literature is whether numerals have a lower bounded, i.e. 'at least' semantics and should therefore be treated on a par with scalar terms like some (see Section 2). On the neo-Gricean view, two is typically incompatible with three - and some with all - because of an upward bounding scalar implicature (i.e. two and not more, some and not all). Interestingly, there is now substantial evidence that preschoolers often do not compute upward bounding scalar implicatures in tasks designed to measure language comprehension (Chierchia et al., 2001; Musolino \& Lidz, 2002; Noveck, 2001; Papafragou \& Musolino, 2003). This fact provides the theorist with an interesting tool to test the predictions of the neo-Gricean account: to the extent that the approach is correct, implicature-insensitive children should treat both some and two as compatible with stronger values on their respective scales, i.e. all and three. Crucially, however, P\&M show that this prediction is not born out (see Section 3). Recall that when presented with a situation in which three horses jumped over a fence, 5-year-olds (unlike 
adults) almost always accepted statements like Some of the horses jumped over the fence as accurate descriptions of the situation. By contrast, when the puppet described the same situation by saying that Two of the horses jumped over the fence, children overwhelmingly corrected the puppet on the grounds that three horses, not two, had jumped over the fence.

These findings clearly demonstrate that 5-year-olds do not represent numerals in the way suggested by the neo-Gricean account. However, recall from the discussion in Section 3 that the implications of P\&M's findings regarding the correct analysis of numerals in the adult grammar cannot not be fully determined until we can tease apart the two options described below, both of which are compatible with P\&M's findings.

\section{Option 1:}

(a) Children and adults have the same semantic representation for numerals and

(b) This representation does not correspond to an 'at least n', neo-Gricean semantics.

\section{Option 2:}

(a) Children and adults have different semantic representations for numerals and

(b) The adult representation of numerals corresponds to an 'at least n', neo-Gricean semantics and

(c) Children initially assign numerals an 'exactly n' semantics and they do not yet have access to the pragmatic mechanisms which yield interval interpretations (i.e. 'at least/most n') from an underlying 'exactly n' semantics.

Armed with the results presented in this study, we are now in a position to tease apart the two scenarios described above - and it should now be clear that option 2 must be abandoned. Let us see why. Recall that our main finding is that by the age of 5 , preschoolers can assign numerals the full range of interpretations available in the adult grammar (i.e. 'exactly n', 'at least n' and 'at most n'). Moreover, showing that 5 -year-olds can assign numerals the full range of interpretations available in the adult grammar amounts to showing that preschoolers and adults have the same semantic representations. These two conclusions falsify premise (c) and premise (a) of option 2 , namely that children are restricted to the exact interpretation of numerals and that their semantic representations differ from those of adults.

Premise (a) of option 1 - the equivalence between the semantic representations of children and those of adults - must therefore hold. We also know from the results of P\&M's study that the representation of numerals in the grammar of 5-year-olds cannot correspond to an 'at least n' semantics. By virtue of the equivalence between the semantic representations of children and adults, we can now push the implications of P\&M's results one step further and conclude that the neo-Gricean approach cannot be the correct analysis of the representation of numerals in the adult grammar either. In other words, if A (children's semantic representation) = B (adults' semantic representation), and $\mathrm{C}$ ( $\mathrm{P} \& \mathrm{M}$ 's results) is incompatible with $\mathrm{A}$, then $\mathrm{C}$ must also be incompatible with $\mathrm{B}$. 
Notice that the results of Experiment 1 of the present study are also problematic for the neo-Gricean view of numerals. Experiment 1 revealed that children have difficulty assigning numerals an 'at least $\mathrm{n}$ ' interpretation in contexts in which adults can easily assign such an interpretation. By contrast, children experienced no difficulty (when compared to adults) with the 'at most n' interpretation. This, in fact, is exactly the opposite of what the 'at least n', neo-Gricean account would predict. That is, since numerals on this view are claimed to have an 'at least n' semantics, one would expect that a 'neo-Gricean' child should have no difficulty accessing the 'at least n' interpretation. Moreover, since it isn't clear how one could derive the 'at most n' interpretation from an underlying 'at least n' semantics (see discussion in Section 2.3), one should expect a neo-Gricean child to experience difficulty with the 'at most n' interpretation, again contrary to fact. Finally, it should be noted that while these results weaken the plausibility of the neo-Gricean account of numerals, they do not allow us to choose between the two major alternatives to the neo-Gricean analysis, namely the underspecified and the punctual semantics approach (see Section 2).

More generally, these results provide a concrete illustration of the importance of data from language acquisition for the construction of explanatory accounts of linguistic structure. As Chomsky (1965) reminds us, "A grammar ... is descriptively adequate [my emphasis] to the extent that it correctly describes the intrinsic competence of the idealized native speaker." (p. 24). However, "On a much deeper and hence much more rarely attainable level (that of explanatory adequacy [my emphasis]), a grammar is justified to the extent that it is a principled descriptively adequate system, in that the linguistic theory with which it is associated selects this grammar over others ... The problem ... of explanatory adequacy ... is essentially the problem of constructing a theory of language acquisition ..." (p. 27). Chomsky (1965) further points out that “... considerations of explanatory adequacy are often critical for advancing linguistic theory" (p. 26). I hope that the results presented here, by allowing us to choose between competing descriptively adequate analyses, have taken us one step further in that direction.

Let us now consider the developmental implications of the results presented in this study. As we observed at the outset of this investigation, work in theoretical linguistics shows that the grammatical knowledge to be acquired in the domain of numeral quantification is considerably more intricate than what current developmental accounts generally assume. Number words, when used as quantificational determiners (what Fuson (1988) calls the cardinal use of number words), give rise to three distinct interpretations, i.e. 'exactly n', 'at least n' and 'at most n', intricate entailment patterns and a range of pragmatic effects (see Section 2). Moreover, the availability of such interpretations is constrained in non-trivial ways: 'non-exact' interpretations only arise when numerals are used distributively and they do so only in specific pragmatic contexts. Thus, the new challenge facing developmental accounts is to explain when and how this intricate system of knowledge arises in the child.

I have begun to address these questions by showing that by the age of 5 children have implicit knowledge of the fact that numerals can receive 'non-exact' interpretations, i.e. 'at least n' and 'at most n'. We may now ask how children 
acquire this knowledge. Before pursuing this question any further, I should make it clear that I do not intend to propose a detailed account of how this may happen. This task falls beyond the scope of the present study and will certainly require further investigation. My purpose here is more modest: I simply wish to discuss two alternative approaches to the 'learning question' and point to what each would have to show in order to provide a satisfactory explanation.

The two cases that I would like to consider are (a) that knowledge of the fact that numerally quantified NPs can receive non-exact interpretations can be induced from an analysis of the input or (b) that this knowledge does not arise from an analysis of the input, but rather, that if follows from the child's a priori expectations regarding the lexical semantics of numerals or, alternatively, from her knowledge of the principles identified by $G \& G$, in conjunction with knowledge of basic rules of semantic composition.

Beginning with option (a), the first question that comes to mind regards the evidence that the child would need in order to arrive at the relevant conclusion. One possibility is that the input contains direct evidence that numerals can receive nonexact interpretations. Such evidence would come in the form of sentences containing numerals used in situations which make the sentence true on the 'at least n' or the 'at most n' interpretation. Sentences that give rise to 'non-exact' interpretations typically contain modals such as need or can. So, for example, children may hear a parent tell them that they can have two cookies (at most two cookies) or that they need to eat two more pieces of broccoli (at least two) to be allowed to have desert. Notice, however, that hearing these sentences by themselves would certainly not be enough for the child to realize that the numerals can receive an 'at least n' or 'at most n' interpretation. In order for the child to realize that two cookies in the example above should be interpreted as at most two cookies, she would need to be shown or told that having only one cookie would also be satisfactory. The same holds of two pieces of broccoli in our example above which should be interpreted as at least two pieces of broccoli. Here, the child would need to be told that eating one piece will not do while eating three, four, etc. would allow her to get desert. The basic problem with sentences containing modals and numerals is that they are not typically used to describe states of affairs which are directly observable. Thus, unless the child is told or shown that numerals are not meant to be interpreted 'exactly' in these cases, it is hard to see how she could arrive at this conclusion.

One possibility, which was pointed out to me by a reviewer, is that children and their parents participate in the kind of verbal interactions shown below:

MOTHER: You have to eat THREE pieces of broccoli to get a cookie.

CHILD: No, FOUR pieces!

MOTHER: (chuckles indulgently) OK, fine.

(vs. the alternative)

MOTHER: You have to eat THREE pieces of broccoli to get a cookie.

CHILD: No, TWO pieces!

MOTHER: No, THREE pieces. 
The idea here would be that the child should somehow deduce from these interactions that three can be interpreted as at least three. That is, since the mother does not object to her child wanting to eat more than three pieces of broccoli in the first dialogue, the child ought to infer that three is compatible with four and thus that three can have an interval reading, i.e. 'at least three'. The second dialogue, by contrast, would inform the child, because of her mother's objection, that three is not compatible with two and hence that numerals have a lower bounded semantics.

The problem with this reasoning is that there is nothing in these hypothetical dialogues that would in fact force the child to conclude that three can mean 'at least three'. To be sure, nothing in the first dialogue would prevent the child from assuming that her mother used three to mean 'exactly three', that four means 'exactly four' and thus to conclude that since 'exactly four' is more than 'exactly three', her mother has no reason to object. That is, the mother has no reason to object to her child wanting to eat more broccoli since the mother's goal is to have her child eat broccoli in the first place. The same reasoning can be applied to the second dialogue which still makes perfect sense on the assumption that both participants intend to use their number words on an exact reading. In sum, short of endowing the child with mind-reading abilities and in the absence of explicit instruction, it is hard to see how the kind of interactions described above could lead the child to conclude that numerals can have non-exact interpretations.

Next, one needs to ask whether the kind of evidence discussed above is indeed available in the input. In order to begin addressing this question, we looked for parental uses of the numeral two in the CHILDES database. Given the age of the children tested in the present study, we tried to find out how parents would use numerals when interacting with 4- and 5-year-olds. We looked at a total of 45 corpora and found 88 pairs of parents/4-5-year-olds. Of these we found 23 pairs where parents used the numeral two and a total of 601 uses of that word. The children were between the ages of $4 ; 0$ and $5 ; 11$. Of these 601 uses we only found two instances where two was used with a modal. ${ }^{9}$ Moreover, the examples do not seem to contain the kinds of explanations that the child would need in order to arrive at the conclusion that numerals can receive 'at least/most n' interpretations (for further evidence along these lines, see Durkin, Shire, Riem, Crowther \& Rutter, 1986). The two examples that we found are reported below.

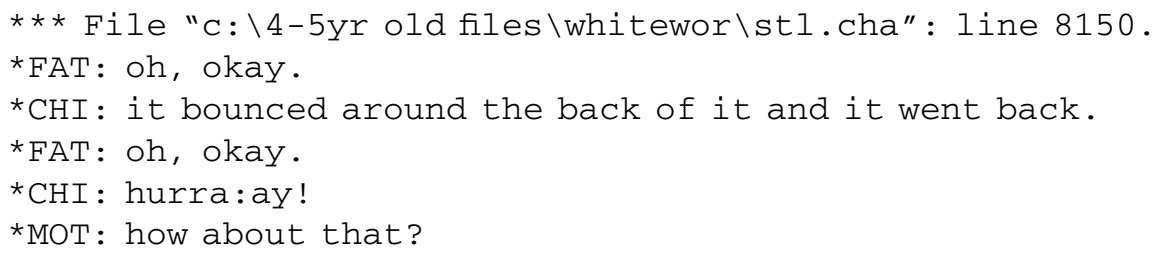

\footnotetext{
9 As one might expect, two was also used as a cardinal (e.g. two hands), a measure phrase (e.g. two hours ago), as part of a counting routine (e.g. one block, two blocks, etc.) or in a sequence (e.g. one, two, three). However, it is hard to see how a child hearing, say "Two hands, yes, you have two hands!" or "one, two, three" could learn that two can receive an 'at least n' or 'at most n' interpretation.
} 


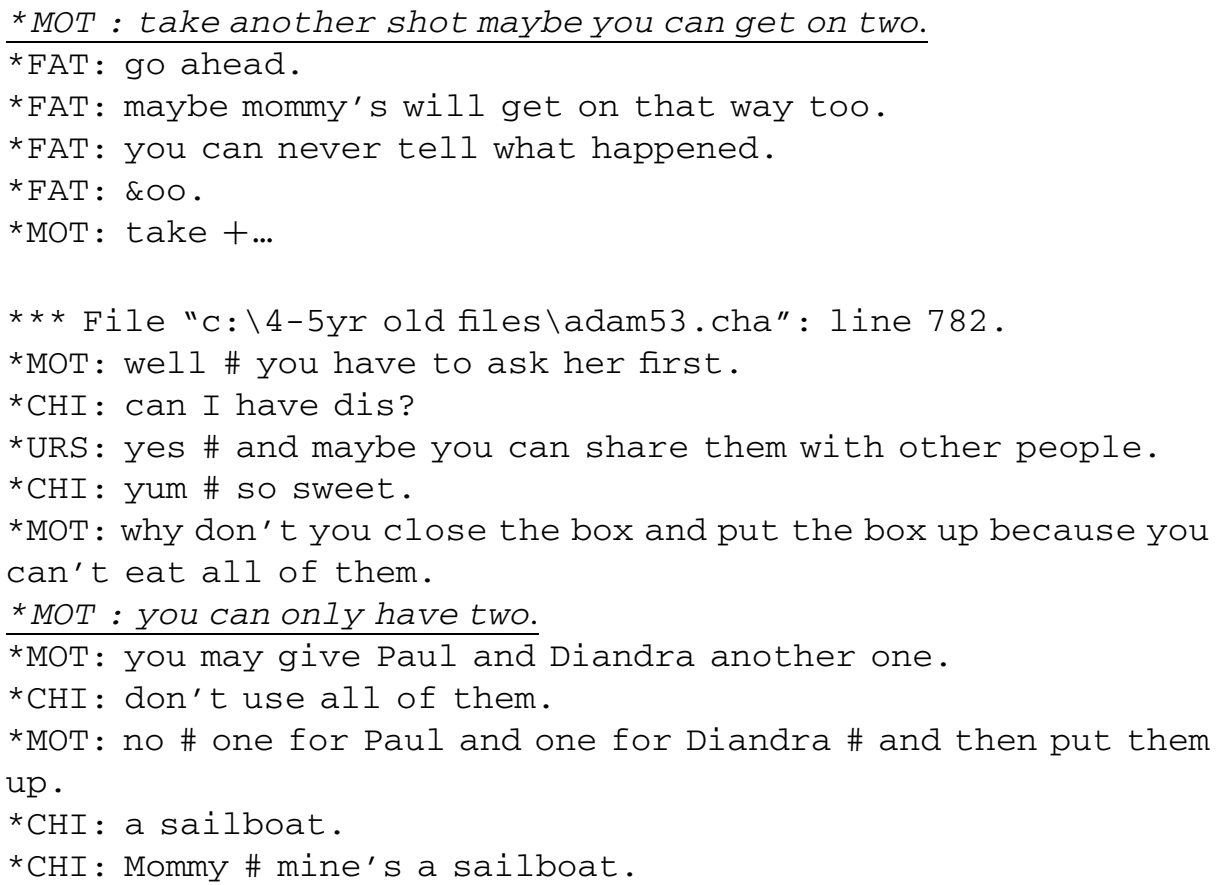

Of course, this kind of evidence is only suggestive. It certainly cannot be taken as definitive proof that children do not receive the kind of input that they would need in order to learn that numerals can receive, in addition to their exact interpretations, an 'at least n' and 'at most n' interpretation. For example, one may also want to look at how parents use other numerals, e.g. one, three, etc. However, the evidence does not look very promising. In order to demonstrate that children do indeed learn that numerals can receive 'non-exact' interpretations from evidence available in the input, one would first need to establish what that evidence might be, as we tried to do above. More importantly, one would need to show that the evidence in question is indeed present in the child's input and specify the conditions under which children could identify and make use of that evidence.

Another possibility is that the input contains indirect evidence that children could rely on to learn that numerals can receive 'non-exact' interpretations. For example, children may learn the meaning of expressions like at least two $N$ and at most two $N$ and use this knowledge as a bootstrap to further refine their hypothesis regarding the meaning of expressions like two $N$. This kind of account faces two important problems however. First, even if 4- and 5-year-olds knew the meaning of expressions like at least/most two $\mathrm{N}$, it is unclear how or why they would conclude that phrases like two $N$ can be used to mean at least/most two $N$. To be sure, two in say, at most two $N$ is interpreted as exactly two. In other words, at most two means [at most [exactly 2]] and not, say [at most [at least two]] which would not make any sense. Thus, if two $N$ in expressions like at least/most two $N$ is interpreted as exactly two $N$, it is hard to see how knowing the meaning of such expressions would lead to the conclusion that two $N$ in phrases like two $N$ can be interpreted 
as at least/most two $N$. Notice that the same argument holds for expressions like up to two and the like.

One might object that these are only theoretical considerations and that knowing the meaning of expressions like at least/most two $N$ would indeed provide the child with the relevant evidence. A much stronger argument against such a view comes from the results of Experiment 3. As I have shown, 4- and 5-year-olds have implicit knowledge of the fact that expressions like two $N$ can receive an 'at least n' or 'at most n' interpretation before they know the meaning of corresponding expressions such as at least two $N$ and at most two $N$. Clearly then, children do not rely on their knowledge of the meaning of expressions like at least/most two $N$ to learn that phrases like two $N$ can also receive such interpretations.

Thus, in order to show that children can learn the properties of numerals under consideration, it is at minimum necessary to demonstrate that the relevant evidence is available in the input. Until this can be done, it is certainly reasonable to entertain the possibility that the relevant properties are not induced from an analysis of the input. After all, a central claim of Generative models of language acquisition is that much of what we know about language cannot be learned from an analysis of the input alone (Chomsky, 1975; Crain, 1991; Hornstein \& Lightfoot, 1981 among many others; for recent experimental evidence, see Lidz, Waxman, \& Freedman, 2003). As Hornstein and Lightfoot (1981) argue "People attain knowledge of the structure of their language for which no evidence is available in the data to which they are exposed as children. Crucial evidence for such knowledge consists of judgments concerning complex and rare sentences ... all of which are available to the linguist but lie outside the primary linguistic data available to the child." (pp. 9-10). Suppose that the behavior of numerals, and in particular the availability of 'non-exact' interpretations, represents one such case. If so, how can children arrive at the correct conclusions? As is well-known, the classic solution to 'poverty of stimulus' problems is to assume that learners bring a priori knowledge to the task of language acquisition. To quote Hornstein and Lightfoot (1981) again "It is reasonable to look for a priori knowledge available to the organism, which permits language acquisition to circumvent the environmental deficiencies and thus to take place." (p. 13).

On this view, the nature of the child's expectations will in turn depend on the correct analysis of numerals. Consider again the proposal that numerals allow 'non-exact' interpretations, i.e. 'at least n' and 'at most n', because they are lexically underspecified (Carston, 1985; see Section 2). If so, to the extent that this property holds crosslinguistically (see Levinson, 2000 for relevant discussion), the child may start with the expectation that what she identifies as a numeral should be assigned an underspecified lexical representation. When composed, this underspecified representation would interact with other expressions (e.g. certain modals) or features of the context whose semantic/ pragmatic content would yield the appropriate interpretation, i.e. 'at least n', 'at most n' and 'exactly n' on a particular occasion of use.

Alternatively, numerals may have an 'exactly n' lexical semantics and acquire their 'at least n' and 'at most n' interpretations only when composed, i.e. at the sentential level (Koenig, 1991). On this scenario, it is crucial that children's rules of composition allow 
them to distinguish between the distributive and the set interpretation of sentences like (28) (I come back to this assumption).

(28) Three boys carried a sofa up the stairs.

a. There is a set M, M a set of boys of cardinality 3, for each boy b in M, b carried a sofa up the stairs.

b. There is a set M, M a set of boys of cardinality 3, M carried a sofa up the stairs.

To the extent that this is the case, the existence of scalar effects and their restricted availability to distributive contexts can be shown to follow from knowledge of the counting principles identified by $G \& G$. Recall that these principles include the 'one-one principle' - requiring a one-to-one correspondence between items in a display and number tags, the 'stable order principle' - requiring that number tags be ordered in the same sequence across trials and the 'cardinal principle' - requiring that the last tag used in a sequence correspond to the cardinality of the set of items in the sequence.

Consider now the scalar entailment in (29) available on the distributive interpretation of Three boys carried a couch up the stairs, i.e. (28a).

(29) Three boys (each) carried a couch up the stairs $\Rightarrow$ Two boys (each) carried a couch up the stairs.

A child who knows that each object in a set must receive a unique number tag, that these tags are ordered in a rigid way, and that the last tag corresponds to the cardinality of the set - in sum a child who understands ordinality - will automatically know that if there is a set of boys $\mathrm{M}$ of cardinality 3, and that for each boy $\mathrm{b}$ in $\mathrm{M}, \mathrm{b}$ carried a couch up the stairs, then there must also be a set of boys of cardinality 2 such that each boy in that set carried a couch up the stairs. In fact, a child who also knows the 'order-irrelevance' principle stating that counting can start with any object in a set - will know that there are precisely three such sets, i.e. three possible sets of two boys such that each boy in that set carried a couch up the stairs. Thus, knowledge of the entailment relation in (29) can be derived from knowledge of the counting principles identified by G\&G through the notion of ordinality. Notice that knowledge of (29) also implies knowledge of the 'at least n' interpretation of numerals (when they are used distributively). In other words, the reason that a question like Does Goofy have two cookies? can be answered affirmatively even when Goofy has exactly three cookies (see Experiment 2) follows from the fact that if Goofy has three cookies, he must also have two cookies.

We can take this argument one step further by following Gallistel and Gelman (1992) who propose that numerical competence in the verbal system depends on the existence of a preverbal system for representing numerosity. The counting principles identified by $G \& G$, in turn, can be derived from the basic principles of numerical computation governing the preverbal system. In Gallistel and Gelman's (1992) own words “The preverbal system for deriving a representation of numerosity - the preverbal counting mechanism - renders the verbal system intelligible by providing a domain-specific isomorphic system to which the verbal system may be mapped. The principles that govern verbal counting are the principles implicit in the structure of the preverbal counting mechanism." (p. 71). Thus, to 
the extent that this proposal is on the right track, one may argue that knowledge of the basic conceptual system underlying our verbal abilities in the domain or number, in conjunction with basic principles of semantic composition - both of which are independently motivated - is enough to explain how children come to know the basic scalar properties of numerals, even in the absence of evidence from the input.

Considerations of the interface between language and number, in turn, may allow us to understand - and even derive - the fact that numerally quantified NPs allow both a distributive and a set interpretation (see discussion above and Section 2). In their discussion of the number-language interface, Grinstead et al. (1998) observe that "the grammar of the count routine differs strikingly from the grammar of what we call clausal syntax" (p. 310). In particular, these authors observe that counting say, five women at a bus stop (to use Grinstead et al.'s example) as in (30), automatically imposes an order on the set of women, in addition to determining the cardinality of the set.

(30) One woman ... two women ... three women ... four women ... five women

However, the ordinal relation expressed in the counting sequence in (30) seems to be lost when number words are used as quantificational determiners, as in (31) (also from Grinstead et al., 1998). The cardinal value of the set, however, is preserved.

(31) a. I saw five women at the bus stop.

b. The five women with blue hats stood at the bus stop.

Grinstead et al. (1998) propose to explain this fact and spell out their view of the numberlanguage interface as follows:

We would like to suggest that this fact follows from properties of the number domain, as expressed by the grammar. The idea would be that the number domain carries out a computation of the kind illustrated with the successor function ... The resulting representation is transferred to an intermediate, "higher order" representation which can be interpreted by the grammatical system as a lexical item, namely a quantifier. This quantifier can then participate in the computations of the grammatical domain to produce clausal utterances such as those in [31]. However, it can also participate in the kind of computation which produces [30]. The count routine utterance represented in [30] appears to have fundamentally different properties than the clausal utterances in a number of ways. The fact, just mentioned, that these representations carry cardinal as well as ordinal numerical properties is an example of such a property. This appears to be a numerical property because counting is a serial process. It is a property of the successor function ... that each successive representation is computed by using the previous representation as an input. Thus ordinality is simply a property of the successor function. (p. 310) ${ }^{10}$

\footnotetext{
10 The successor function is what lies at the heart of the recursive nature of number and it can be defined as a function $s$, such that for any number $n, s(n)=n+1$.
} 
In fact, the penetration of the number system into the grammar of natural language may even run deeper than Grinstead et al. suggest and extend to certain aspects of the behavior of numerally quantified NPs in clausal syntax. On this view, the fact that numerally quantified NPs can receive both a distributive and a set interpretation receives an immediate explanation: language behaves the way it does in this case precisely because, as Grinstead et al. (1998) argue, "cognitive architecture allows insertion of lexical items into the computational system of grammar which carry properties particular to the number domain with them. Thus, the lexicon allows quantifiers and nouns to express properties of numerical domain" (p. 311). Specifically, the distributive and set reading of numerally quantified NPs can be seen to follow from two fundamental properties of the number system: ordinality and cardinality, respectively (see above discussion).

\section{Concluding remarks}

The goal of this study was to bring together two independent lines of research on numerally quantified NPs and to show that when integrated, these two perspectives can both constrain and enrich each other. Specifically, I have tried to show that (a) the linguistic behavior of number words is more complex than developmental accounts currently assume, (b) however intricate, the intuitions and analyses of theoretical linguists can nevertheless be tested experimentally, (c) the incompatibility of the results presented here with the standard, neo-Gricean account of numerals will make these results useful to theorists concerned with the proper analysis of such expressions, (d) by the age of 5 children possess sophisticated semantic and pragmatic knowledge in the domain of number and (e) a new challenge for developmental accounts is to explain how such intricate knowledge arises in the child.

\section{Acknowledgements}

I would like to thank Lia Ozolins, Amy Blouin (Director and Associate Director) as well as the staff and children at the Prep School, a preschool in the Bloomington area. Thanks are also due to Nancy Melhorn, Diana Lake, Stacey Mundy and the children at the Bloomington Developmental Learning Center. Finally, I wish to thank the students at Indiana University who helped me collect the data presented in this study: Jamie Modrak, Jami Goodman, Kelly Urbanczyk, Jennifer O'Donnell, and Marissa Schneider. None of the work reported here would have been possible without the help of all these people. 


\section{Appendix A. Patterns of correct responses for the conditions described in Experiment 3}

The patterns of correct responses for the conditions described in Experiment 3 are given in Tables $\mathrm{A} 1-\mathrm{A} 4$.

Table A1

At least two

\begin{tabular}{|c|c|c|c|c|c|c|}
\hline Cards & $0 \mathrm{n}$ & $1 \mathrm{n}$ & $2 \mathrm{n}$ & $3 n$ & $4 \mathrm{n}$ & $5 \mathrm{n}$ \\
\hline Expected response & No & No & Yes & Yes & Yes & Yes \\
\hline
\end{tabular}

Table A2

Exactly two

\begin{tabular}{|c|c|c|c|c|c|c|}
\hline Cards & $0 \mathrm{n}$ & $1 \mathrm{n}$ & $2 \mathrm{n}$ & $3 n$ & $4 n$ & $5 \mathrm{n}$ \\
\hline Expected response & No & No & Yes & No & No & No \\
\hline
\end{tabular}

Table A3

At most two

\begin{tabular}{|c|c|c|c|c|c|c|}
\hline Cards & $0 \mathrm{n}$ & $1 \mathrm{n}$ & $2 n$ & $3 n$ & $4 \mathrm{n}$ & $5 n$ \\
\hline Expected response & Yes & Yes & Yes & No & No & No \\
\hline
\end{tabular}

Table A4

More than two

\begin{tabular}{|c|c|c|c|c|c|c|}
\hline Cards & $0 \mathrm{n}$ & $1 \mathrm{n}$ & $2 n$ & $3 n$ & $4 \mathrm{n}$ & $5 \mathrm{n}$ \\
\hline Expected response & No & No & No & Yes & Yes & Yes \\
\hline
\end{tabular}

\section{References}

Atlas, J (1990). Implicature and logical form: the semantics-pragmatics interface, Lecture 3. Manuscript of lecture delivered at second European summer school in language, logic and information, Katholieke Universiteit Leuven.

Bloom, P. (2000). How children learn the meanings of words. Cambridge, MA: MIT Press.

Bloom, P., \& Wynn, K. (1997). Linguistic cues in the acquisition of number words. Journal of Child Language, 24, 511-533.

Briars, D. J., \& Siegler, R. S. (1984). A featural analysis of preschoolers' counting knowledge. Developmental Psychology, 20, 607-618.

Carey, S. (2001). Cognitive foundations of arithmetic: evolution and ontogenesis. Mind and Language, 16, 37-55.

Carston, R (1985). A reanalysis of some 'quantity implicatures'. Unpublished manuscript, University College London.

Carston, R. (1998). Informativeness, relevance and scalar implicature. In R. Carston, \& S. Uchida (Eds.), Relevance theory: applications and implications. Amsterdam: Benjamins. 
Chierchia, G., Crain, S., Guasti, M. T., Gualmini, A., \& Meroni, L. (2001). The acquisition of disjunction: evidence for a grammatical view of scalar implicatures. In A. H.-J. Do, L. Dominguez, \& A. Johansen (Eds.), (pp. 157-168). Proceedings of the 25th annual Boston University conference on language development, Somerville, MA: Cascadilla Press.

Chomsky, N. (1959). A review of B.F. Skinner's Verbal Behavior. Language, 35, 26-58.

Chomsky, N. (1965). Aspects of the theory of syntax. Cambridge, MA: MIT Press.

Chomsky, N. (1975). Reflections on language. New York: Pantheon.

Crain, S. (1991). Language acquisition in the absence of experience. Behavioral and Brain Sciences, 14, 597650 .

Crain, S., \& Thornton, R. (1998). Investigations in universal grammar: a guide to research on the acquisition of syntax and semantics. Cambridge, MA: MIT Press.

Dehaene, S. (1997). The number sense: how the mind creates mathematics. New York: Oxford University Press.

Durkin, K., Shire, B., Riem, R., Crowther, R. D., \& Rutter, D. R. (1986). The social and linguistic context of early number word use. British Journal of Developmental Psychology, 4, 269-288.

Freeman, N. H., Antonucci, C., \& Lewis, C. (2000). Representation of the cardinality principle: early conception of error in a counterfactual test. Cognition, 74, 71-89.

Fuson, K. (1988). Children's counting and concepts of number. New York: Springer-Verlag.

Gallistel, C. R., \& Gelman, R. (1992). Preverbal and verbal counting and computation. Cognition, 44, 43-74.

Gazdar, G. (1979). Pragmatics. New York: Academic Press.

Gelman, R. (1993). A rational-constructivist account of early learning about numbers and objects. In D. Medin (Ed.), (30) (pp. 61-96). Learning and motivation, New York: Academic Press.

Gelman, R., \& Cordes, S. A. (2001). Counting in animals and humans. In E. Dupoux (Ed.), Language, brain, and cognitive development; essays in honor of Jacques Mehler. Cambridge, MA: MIT Press.

Gelman, R., \& Gallistel, C. R. (1978). The child's understanding of number. Cambridge, MA: Harvard University Press.

Gelman, R., \& Meck, E. (1983). Preschoolers' counting: principles before skill. Cognition, 13, 343-359.

Grice, P. (1989). Studies in the way of words. Cambridge, MA: Harvard University Press.

Grinstead, J., MacSwan, J., Curtiss, S., \& Gelman, R. (1998). The independence of language and number. In A. Greenhill, M. Hughes, H. Littlefield, \& H. Walsh (Eds.), (pp. 303-313). Proceedings of the 22nd annual Boston University conference on language development, Somerville, MA: Cascadilla Press.

Gualmini, A (2003). Children don't lack some knowledge. Manuscript submitted for publication.

Harnish, R. (1976). Logical form and implicature. In T. Bever, J. Katz, \& T. Langedoen (Eds.), An integrated theory of linguistic ability (pp. 313-391). New York: Crowell.

Hirschberg, J (1985). A theory of scalar implicature. Doctoral dissertation, University of Pennsylvania, Philadelphia, PA.

Horn, L (1972). On the semantic properties of the logical operators in English. Doctoral dissertation, UCLA. Distributed by IULC, Indiana University, Bloomington, IN.

Horn, L. R. (1989). A natural history of negation. Chicago, IL: University of Chicago Press.

Horn, L. (1992). The said and the unsaid. In C. Barker, \& D. Dowty (Eds.), (pp. 163-192). Proceedings of SALT II, Columbus, OH: Department of Linguistics, Ohio State University.

Hornstein, N., \& Lightfoot, D. (1981). Introduction. In N. Hornstein, \& D. Lightfoot (Eds.), Explanations in linguistics: the logical problem of language acquisition (pp. 9-31). London: Longman.

Kadmon, N. (2001). Formal pragmatics. Oxford: Blackwell.

Koenig, J. (1991). Scalar predicates and negation: punctual semantics and interval interpretations (pp. 140-155). Proceedings of the parasession on negation of the 27th meeting of the Chicago Linguistics Society, Chicago, IL: Chicago Linguistics Society.

Levinson, S. (2000). Presumptive meanings. Cambridge, MA: MIT Press.

Lidz, J., \& Musolino, J. (2002). Children's command of quantification. Cognition, 84, 113-154.

Lidz, J., Waxman, S., \& Freedman, J. (2003). What infants know about syntax but couldn't have learned: experimental evidence for syntactic structure at 18 months. Cognition, 89, B65-B73.

Michie, S. (1984). Why preschoolers are reluctant to count spontaneously. British Journal of Developmental Psychology, 2, 347-358.

Mill, J. S. (1867). An examination of Sir William Hamilton's philosophy. 3rd edition, London: Longman. 
Mix, K. S. (1999). Preschoolers' recognition of numerical equivalence: sequential sets. Journal of Experimental Child Psychology, 74, 309-332.

Mix, K., Huttenlocher, J., \& Levine, S. (2002). Quantitative development in infancy and early childhood. New York: Oxford University Press.

Musolino, J., Crain, S., \& Thornton, R. (2000). Navigating negative quantificational space. Linguistics, 38(1), $1-32$.

Musolino, J., \& Lidz, J. (2002). Preschool logic: truth and felicity in the acquisition of quantification. In B. Skarabela, S. Fish, \& A. H.-J. Do (Eds.), Proceedings of the 26th annual Boston University conference on language development, Somerville, MA: Cascadilla Press.

Noveck, I. (2001). When children are more logical than adults: experimental investigations of scalar implicature. Cognition, 78, 165-188.

Papafragou, A., \& Musolino, J. (2003). Scalar implicatures: experiments at the syntax semantics interface. Cognition, 86, 253-282.

Richardson, J. F., \& Richardson, A. W. (1990). On predicting pragmatic relations (pp. 498-508). Proceedings of the 16th annual meeting of the Berkeley Linguistic Society, Parasession on the legacy of Grice, Berkeley, CA: Berkeley Linguistic Society.

Sadock, J. (1984). Whither radical pragmatics? In D. Schiffrin (Ed.), Meaning, form and use in context: linguistics applications. Georgetown University Roundtable (pp. 139-149). Washington, DC: Georgetown University Press.

Sarnecka, B., \& Gelman, S (in press). Six does not just mean a lot: preschoolers see number words as specific. Cognition.

Spelke, E. S., \& Tsivkin, S. (2001). Language and number: a bilingual training study. Cognition, 78, 45-88.

Sperber, D., \& Wilson, D. (1995). Relevance: communication and cognition (2nd ed.). Cambridge, MA: Harvard University Press.

Starkey, P., \& Cooper, R. G. (1980). Perception of numbers by human infants. Science, 210, 1033-1035.

Strauss, M. S., \& Curtis, L. E. (1981). Infant perception of numerosity. Child Development, 52, 1146-1152.

Van Loosbroek, E., \& Smitsman, A. W. (1990). Visual perception of numerosity in infancy. Developmental Psychology, 26, 916-922.

Wynn, K. (1990). Children's understanding of counting. Cognition, 36, 155-193.

Wynn, K. (1992). Children's acquisition of number words and the counting system. Cognitive Psychology, 24, 220-251.

Xu, F., \& Spelke, E. (2000). Large number discrimination in 6-month-old infants. Cognition, 74, B1-B11. 